\title{
Interplay Between Melt Flow and the 3D Distribution and Morphology of Fe-Rich Phases in AISi Alloys
}

\begin{abstract}
PIOTR MIKOLAJCZAK and LORENZ RATKE
The presence of Fe aids in establishing the mechanical and physical properties of AlSi alloys and is also one of the main impurities leading to formation of $\beta-\mathrm{Al}_{5} \mathrm{FeSi}$ intermetallics. This study aims to understand the effect of fluid flow on the dendritic microstructure with intermetallics in Al-5/7/9 wt pet Si-0.2/0.5/1.0 wt pet Fe alloys that are directionally solidified under defined thermal and fluid flow conditions. We made extensive use of 3D X-ray tomography to obtain a better insight into the morphology and formation of the intermetallics. Three-dimensional (3-D) distribution of intermetallics presented here shows that the growth of large $\beta-\mathrm{Al}_{5} \mathrm{FeSi}$ due to forced flow occurs in the eutectic specimen center and together with an increase in the number density of $\beta$ precipitates. The 3D reconstructions have verified the $\beta$ shaped to be curved, bent with twining, branched, and to have imprints, holes, and propeller-shaped platelets. The 3D views showed that hole-shaped $\beta$ arose from the lateral growth around $\alpha$-Al dendrites. These views also confirmed the phenomenon of shortening of $\beta$ as an effect of flow in the dendritic region, where $\beta$ could be fragmented or completely remelted, and ultimately resulting in microstructures with shorter $\beta-\mathrm{Al}_{5} \mathrm{FeSi}$ and increases in number density. The analysis revealed an interaction between melt flow, 3D distribution, and the morphology of $\beta$ - $\mathrm{Al}_{5} \mathrm{FeSi}$. The growth of a large and complex group of $\beta$ intermetallics can reduce the melt flow between dendrites and strengthen pore nucleation and eutectic colonies nucleation, leading to lower permeability of the mushy zone and increased porosity in the castings.
\end{abstract}

DOI: $10.1007 / \mathrm{s} 11661-014-2692-4$

(C) The Author(s) 2014. This article is published with open access at Springerlink.com

\section{INTRODUCTION}

AL-SI base alloys are widely used in the automotive and aerospace industry, as well as in general engineering industries. They are now steadily replacing many conventional ferrous alloys due to their excellent combination of properties such as low coefficient of thermal expansion, high strength-to-weight ratio, good corrosion resistance and weldability, and minimum energy requirement for recycling. The microstructure of these alloys in the as-cast condition consists of primary grains of $\alpha$-Al with interdendritic regions of Al-Si eutectic. Alloys containing Mn, Fe, $\mathrm{Mg}$, and $\mathrm{Cu}$ also have various other phases present. The grain size, primary dendrite arm spacing (PDAS), secondary dendrite arm spacing (SDAS), size and distribution of secondary phases, porosity, and precipitates that lead to age hardening are all parameters that control the mechanical properties of cast parts.

The use of recycled aluminum containing even small amounts of iron causes the formation of Fe-rich phases $^{[1-3]}$ because of the very low solubility of this

PIOTR MIKOLAJCZAK, Assistant Professor, is with the Institute of Materials Technology, Poznan University of Technology, Piotrowo 3, 60-965 Poznan, Poland, and also with the Institut für Materialphysik im Weltraum, German Aerospace Center DLR, Linder Höhe, 51147 Cologne, Germany. Contact e-mail: Piotr.Mikolajczak@put. poznan.pl LORENZ RATKE, Professor, is with the Institut für Werkstoff-Forschung, German Aerospace Center DLR, Linder Höhe, 51147 Cologne, Germany.

Manuscript submitted June 23, 2014.@

Article published online December 6, 2014 element in $\alpha$-Al (max. 0.05 wt pct). The earliest optical studies reported a wide variety of AlFeSi particles that were classified into three morphologies: polyhedral crystals, Chinese script, or thin platelets (needles in two-dimensional optical micrographs). Most of these phases were than characterized, ${ }^{[1]}$ with the equilibrium phases in low-alloyed Al-Fe-Si material reported as ${ }^{[2-4]}$ $\theta-\mathrm{Al}_{3} \mathrm{Fe}$ (monoclinic), $\alpha-\mathrm{Al}_{8} \mathrm{Fe}_{2} \mathrm{Si}$ (hexagonal), and $\beta-\mathrm{Al}_{5} \mathrm{FeSi}$ (monoclinic). The $\alpha$ phase has also been reported with a composition of $\mathrm{Al}_{12} \mathrm{Fe}_{3} \mathrm{Si}_{2}$ (30.7 wt pct $\mathrm{Fe}, 10.2 \mathrm{wt}$ pct $\mathrm{Si}$ ). These phases are dominant in slowly cooled castings, whereas the metastable phases such as $\mathrm{Al}_{6} \mathrm{Fe}$ (orthorhombic) and $\alpha-\mathrm{Al}_{20} \mathrm{Fe}_{5} \mathrm{Si}_{2}$ (cubic) occur in rapidly quenched material.

The most frequent $\mathrm{Fe}$-rich phase in AlSi casting alloys is $\beta-\mathrm{Al}_{5} \mathrm{FeSi}$ (labeled also as $\beta$ - $\mathrm{AlFeSi}, \beta$, platelet, needle, $\beta$ precipitate) which is hard and brittle and has detrimental influences on the alloy properties. Precipitates of this phase are associated with porosity ${ }^{[5,6]}$ and reduced fluidity, ${ }^{[7]}$ and they act as stress concentrators, ${ }^{[8,9]}$ promoting crack initiation and shortening fatigue life. The presence of $\beta-\mathrm{Al}_{5} \mathrm{FeSi}$ intermetallics increases hardness and reduces impact strength and machinability, but also lowers the soldering of the casting in permanent molds and high pressure die casting. The possibility of changing $\beta$ - $\mathrm{Al}_{5} \mathrm{FeSi}$ plates into less harmful phases having more compact morphology (e.g., Chinese script $\mathrm{t}^{[10]}$ ) is one way to obtain better quality of the castings.

Recent advances in materials characterization can be attributed to developments in three-dimensional visual- 
ization using computerized serial sectioning, X-ray microtomography, and focused ion beam (FIB) techniques, and this type of characterization is increasingly applied in studies on nucleation, ${ }^{[1]}$ growth, ${ }^{[12]}$ coarsening, ${ }^{[13]}$ deformations, ${ }^{[14]}$ and phase formation. ${ }^{[15]}$

Only a few tomographic investigations have been performed on the $\beta$ phases in concentrated AlSi alloys (i.e., the studies by Terzi, ${ }^{[16]}$ Dinnis, ${ }^{[17]}$ Timpel $^{[18]}$ and Puncreobutr $\left.{ }^{[19]}\right)$. The available literature lacks a 3D visualization of $\beta$ platelets in typical cast alloys with different $\mathrm{Si}$ and $\mathrm{Fe}$ concentrations, so little is known regarding the morphology of intermetallics and interactions with primary $\alpha-\mathrm{Al}$ and AlSi eutectics. The present study used X-ray tomography to obtain information about intermetallics on the microscale. The advantage of the current study is the application of a non-destructive method with X-ray tomography giving insight into the 3D microstructure without destruction. The deep etching technique ${ }^{[20,21]}$ also allows to show the intermetallics but with destroying of their spatial, possible location to dendrites and other intermetallics and in the very restricted area. An advantage and uniqueness of the current investigation compared to the existing studies ${ }^{[16-19]}$ is the application of perfectly controlled solidification and flow conditions conducted in the Artemis ${ }^{[22-24]}$ facility. The microstructures produced by use of a controlled temperature gradient, cooling rate, and solidification front velocity allow the assessment of the designed microstructures and establishment of the relationship to similar structures formed in real castings.

The artificial melt flow generated, for example, by a rotating magnetic field (RMF) has been shown to change $\beta$ platelets in less harmful precipitates. ${ }^{[25-27]}$ The present paper studies fluid flow effects during directional solidification of Al-Si alloys with Fe intermetallics using three-dimensional visualization methods. $\mathrm{X}$-ray tomography aided the assessment of the stirring effect on the intermetallics and microstructure in AlSi alloys.

We have chosen nine Al-5/7/9 wt pet Si-0.2/0.5/ 1.0 wt pct $\mathrm{Fe}$ alloys because they contain different volume fractions of eutectic, which facilitates the investigation of the effects on the $\beta$ phase of different dendritic structures, flow conditions, and density of Ferich phases. The relevant part of the ternary phase diagram is shown in Figure 1.

\section{EXPERIMENTAL}

This study investigates nine aluminum alloys with 5 , 7, and 9 wt pet $\mathrm{Si}$ and $0.2,0.5$, and 1.0 wt pet $\mathrm{Fe}$ prepared from pure components: Al (99.999 pct Hydro Aluminum Deutschland $\mathrm{GmbH}$ ), Si (Crystal Growth Laboratory, Berlin, Germany), and Fe from ferroaluminum (50 wt pet Al-50 wt pet Fe, Goodfellow Cambridge Ltd, U.K.). These nine alloys are located with solid dots on the liquidus projection of the Al-corner of the Al-Fe-Si system in Figure 1. The melt was prepared in an electric resistance furnace using a graphite crucible (30 $\mathrm{mm}$ inner diameter) and degassed with argon. From the beginning of the melting process, a continuous flux

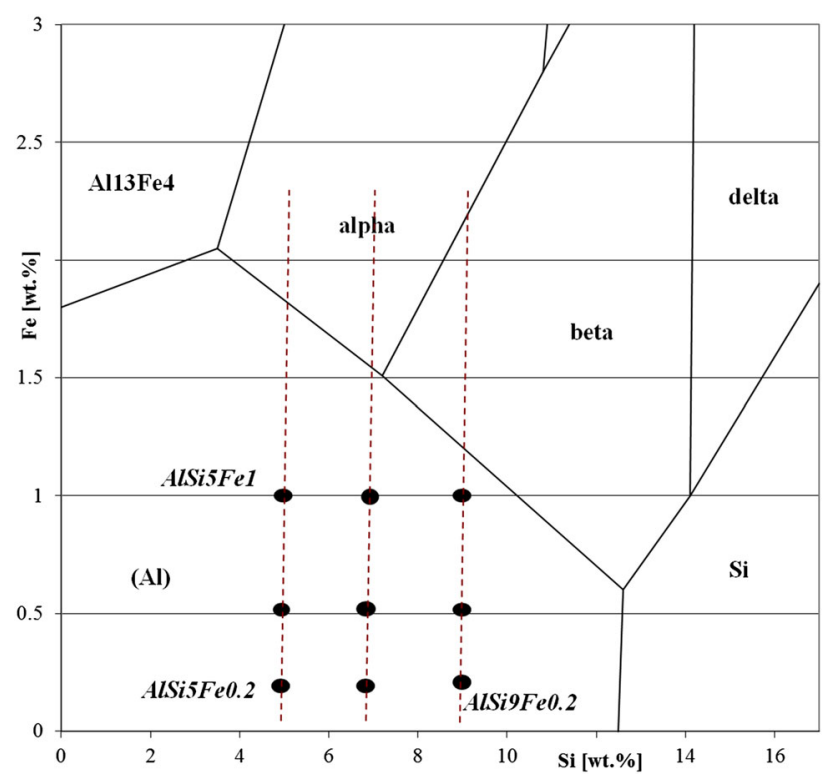

Fig. 1-Plot of the Al-rich corner of the liquidus projection of the Al-Fe-Si system. Filled black dots represent the nominal concentrations of the studied AlSi5/7/9Fe0.2/0.5/1.0 alloys.

of argon flushed the crucible, and after melting, the components were injected through a ceramic pipe with inner diameter $2 \mathrm{~mm}$ to degas the melt. No modifier was used. The molten alloys were poured into stainless steel molds into the shape of cylinders $(12 \mathrm{~mm}$ diameter, $130 \mathrm{~mm}$ length) and machined to samples of $8 \mathrm{~mm}$ diameter and $120 \mathrm{~mm}$ length.

This shape and dimension was suitable for the Artemis-3 facility, which allows directional solidification of metallic alloys under controlled conditions. ${ }^{[22-24]}$ In principle, the Artemis setup consists of two heating elements separated by a piece of silica aerogel as a thermal isolating crucible and a cooling element, with the specimen contained within the crucible. The two furnaces are controlled independently (LabView Software) and set to ensure a constant solidification velocity, cooling rate, and a temperature gradient. ${ }^{[25-27]}$ Three pairs of coils located very close to the sample can yield a magnetic field of up to $6 \mathrm{mT}$ at a frequency of $50 \mathrm{~Hz}$, which induces azimuthal flow as well as secondary flows in the radial and axial directions inside the specimen. ${ }^{[28,29]}$ These flow velocities are around $10 \mathrm{~mm} / \mathrm{s}$. The extremely low thermal conductivity of the aerogel crucible creates planar isotherms in the solidifying specimens, and the transparency allows optical monitoring of the solidification velocity. The specimens were solidified directionally upwards with a temperature gradient $G=3 \mathrm{~K} / \mathrm{mm}$ and solidification velocity $v=0.04 \mathrm{~mm} / \mathrm{s}$, with and without a RMF.

The eighteen solidified samples were cut horizontally (perpendicular to the growth directions), $50 \mathrm{~mm}$ from the bottom heater. Then from this section $(8 \mathrm{~mm}$ diameter, Figure 2), a specimen with a needle shape (with a square cross sect. $0.9 \times 0.9 \times 8.0 \mathrm{~mm}$ ) was machined out. The three-dimensional measurements were done with a Phoenix nanotom ${ }^{\mathrm{TM}} \mathrm{X}$-ray tomography system (Phoenix |X-Ray GmbH) with a $180 \mathrm{kV} / 15 \mathrm{~W}$ 


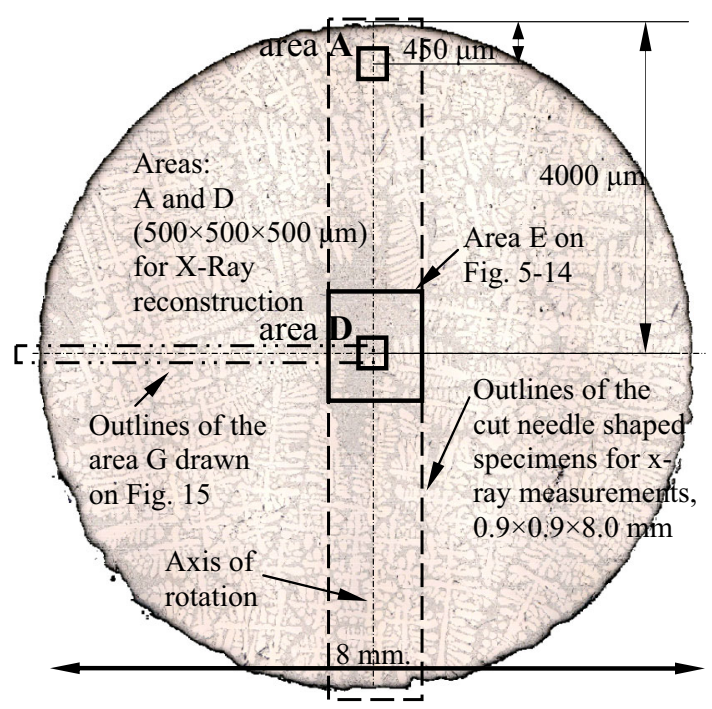

Fig. 2-Scheme of cut needle-shaped specimens prepared for X-ray tomography measurement. Reconstruction areas $A, D$ and $E$ and $G$. Specimen of Al-7 wt pet Si-1.0 wt pet Fe $(B=6 \mathrm{mT}, f=50 \mathrm{~Hz})$.

ultrahigh performance nanofocus X-ray tube at a voltage of $140 \mathrm{kV}$ and a current of $40 \mu \mathrm{A}$. The needleshaped specimen (Figure 2) was rotated round its long axis to study the volumes marked area $A, D$, and $E$. The inaccuracy of specimen positioning meant that each specimen's axis of rotation (Figure 2) was not completely coincident with the axis of rotation during measurement (of the rotating table by the tomograph), so that the final area of the projection was about $2 \mathrm{~mm}$ wide instead of $1.27 \mathrm{~mm}$. The use of a detection of $2304 \times 2304$ pixels led to a resolution of $1.0 \mu \mathrm{m}$. A total of 800 radiographs were acquired for each needle over a 360 degree rotation ( 3 seconds per projection). Image corrections and ring artifact corrections were applied before the final three-dimensional reconstruction.

The information gathered in a full scan was reconstructed using "datos $\mid \mathrm{x}$-reconstruction v 1.5.022" software (GE Sensing and Inspection $\mathrm{GmbH}$ ), and the image analysis was performed using VGStudio Max 1.2 and myVGL 2.1 (Volume Graphics GmbH, Germany) and processed with Gauss filter. Volume segmentation was carried out by choosing suitable gray levels and applying global thresholding. The advantage of the method applied here in comparison with a synchrotron X-ray beam line is that the intermetallics are visible even when not aligned edge on to the beam, and the method is quicker in comparison with metallographic serial sectioning.

The microscopic observations were performed with an optical microscope (Axio Imager, Carl Zeiss, Germany) and in a SEM (LEO 1530 VP). The composition of phases and across specimens was investigated with EDX (Oxford INCA System). The average composition of alloy was measured with spectrometer before the segregation occurred (before directional solidification).

The Al-rich corner of the AlSiFe-phase diagram (Figure 1) shows that the $\beta-\mathrm{Al}_{5} \mathrm{FeSi}$ phase will always appear as a secondary phase after primary solidification of $\alpha-\mathrm{Al}$ at all $\mathrm{Si}$ concentrations and for Fe concentrations of 0.5 and $1 \mathrm{wt}$ pct. A secondary eutectic forma- tion of $\alpha$-AlSiFe might occur only for low $\mathrm{Fe}$ concentrations and the lowest Si concentration.

\section{RESULTS}

The microstructure of cross sections of the solidified specimens was investigated in $2 \mathrm{D}$, together with measurement of the chemical composition from the aspect of a ternary Al-Si-Fe phase diagram. X-ray tomography was focused on the 3D distribution of Fe-rich intermetallics as an effect of fluid flow and chemical composition. The three-dimensional morphology of the $\beta$ phases was also precisely examined.

\section{A. Overall Effects of Alloy Composition and Fluid Flow on Microstructure}

Figure 3 shows an optical micrograph of a typical structure obtained during a directional solidification run in Artemis 3 for the Al-7 wt pet Si-1.0 wt pet Fe alloy solidified by a rotating magnetic field RMF. Figure 3(b) shows $\alpha$-Al dendrites (white), ( $\alpha$-Al)-Si eutectic (gray), and $\beta$ phases (dark gray) in the form of needles spread over the entire sample and only slightly visible, very small $\beta$ needles. A characteristic feature of this sample (Figure 3(a)) is a $\mathrm{Si}$ and Fe segregation (EDX measurements) represented by the increased eutectic volume fraction in the center. This was observed in all specimens solidified with melt stirring in the present study, as well as in some earlier studies. ${ }^{[25,30]}$ Samples solidified without RMF showed dendrites and eutectic evenly spread in the cross section (data not shown).

The segregation phenomena caused by stirring changed the nominal initial alloy composition across the specimen in the outer ring (area $A$ ) and in the center of the specimen (area $D$ ), as presented in the Al-rich corner of the ternary Al-Si-Fe phase diagram (Figure 4). The AlSi5 base alloys with $0.2,0.5$, and $1.0 \mathrm{wt}$ pct Fe showed a $\mathrm{Si}$ segregation induced by fluid flow with a $\mathrm{Si}$ concentration of 4.5 pct in the outer ring of the specimen and 9.0 pct in the center. The segregation in the AlFel with 5, 7, and 9 wt pet Si changed the Fe concentration to 0.90 pct in the outer ring and 1.80 pct in the center. The small black circles in Figure 4 represent the nominal concentrations of the alloys studied (shown previously in Figure 1), while the filled black dots (and arrows) represent the change in concentration of $\mathrm{Si}$ and $\mathrm{Fe}$ as a result of flow-induced segregation in the specimen center (an increase in $\mathrm{Si}$ and $\mathrm{Fe}$ content) and in the outer dendritic ring (a decrease in $\mathrm{Si}$ and Fe content).

Two-dimensional SEM micrographs exhibit both $\beta$-needles (Figure 3(b)) and $\alpha$-AlSiFe shaped as blocks and Chinese script structures. The length of the $\beta$-phase particles was typically between 5 and $200 \mu \mathrm{m}$, and the number density was 400 to $500 \mu \mathrm{m}^{-2}$ (area $A$ ) or 800 to $1200 \mu \mathrm{m}^{-2}$ (area $D$ ). ${ }^{[30]}$ The phases were composed of 69.6 at. pct Al, 13.6 at. pct Fe, and 18.8 at. pct $\mathrm{Si}^{[31,32]}$ (specimens for AlSi5Fe0.5 with solidified fluid flow) measured with EDX in SEM. Chinese script phases with a composition of 69.7 at. pet A1, 19.0 at. pet Fe, and 11.3 at. pct $\mathrm{Si}$ could also be observed (specimens for 


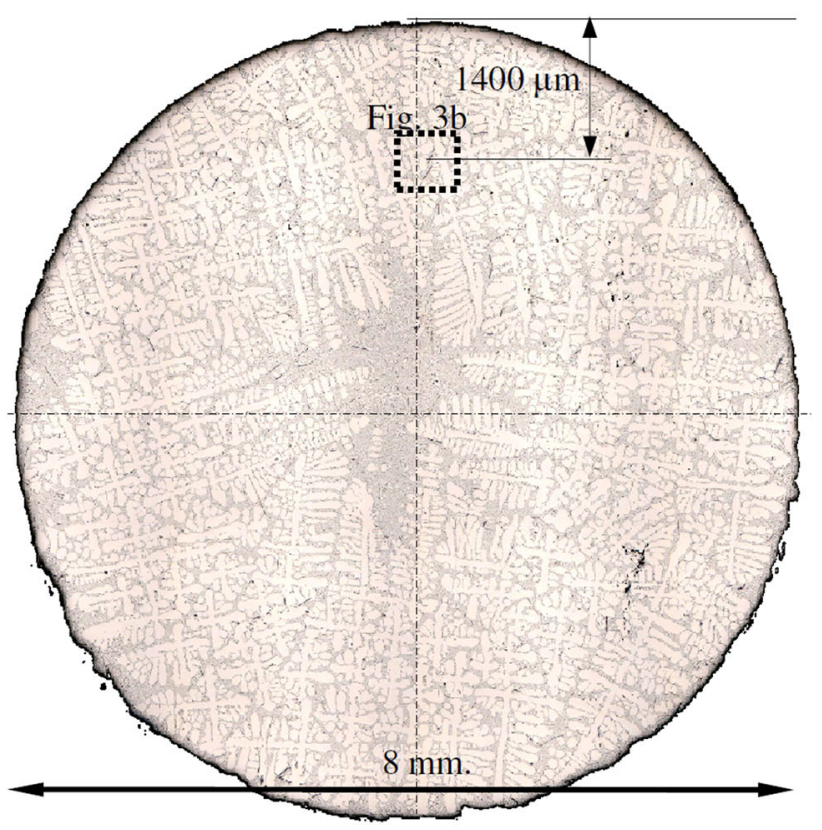

(a)

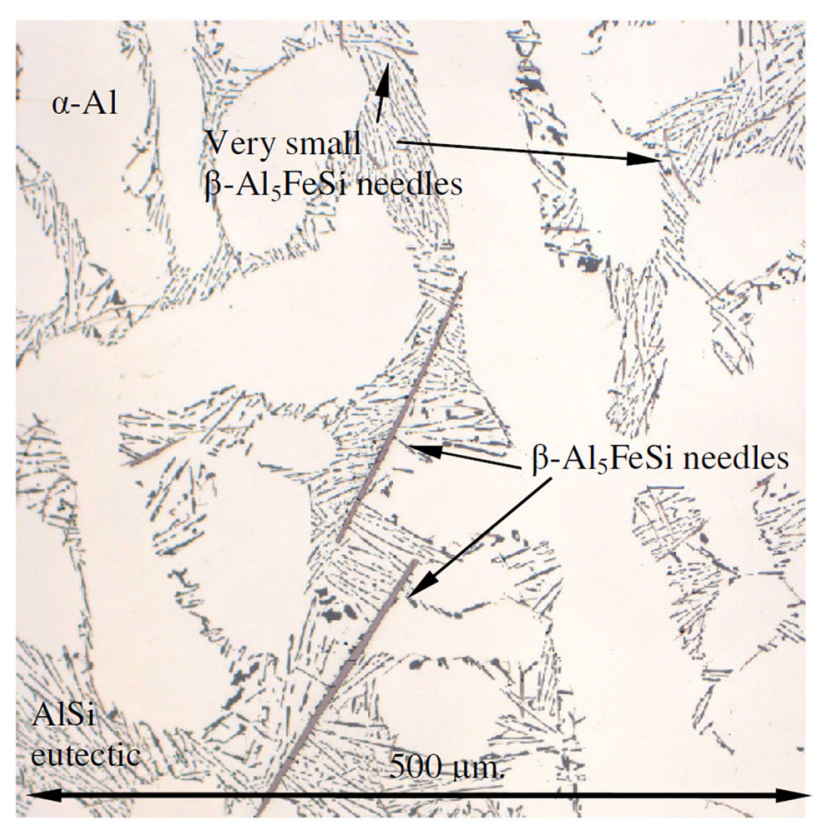

(b)

Fig. 3-Microstructure on the cross section of the specimen of Al-7 wt pet Si-1.0 wt pet Fe solidified under influence of a rotating magnetic field RMF $(B=6 \mathrm{mT}, f=50 \mathrm{~Hz}, \quad G=3 \mathrm{~K} / \mathrm{mm}$, $v=0.040 \mathrm{~mm} / \mathrm{s}$ ). Optical microscope: (a) magnification 50, (b) magnification 200, enlarged detail from (a).

AlSi9Fe 0.5 with fluid flow). The number density reached 5 to $20 \mu \mathrm{m}^{-2}$ (both in area $A$ or $D$ ) for AlSi7Fe0.5, for example, with or without fluid flow. ${ }^{[30]}$

\section{B. Alloy Composition and Flow Effect on the 3D Distribution of $\mathrm{Fe}$-Rich Intermetallics}

Solidified specimens for X-ray tomography were cut to the dimensions of $0.9 \times 0.9 \times 8.0 \mathrm{~mm}$ (Figure 2) and

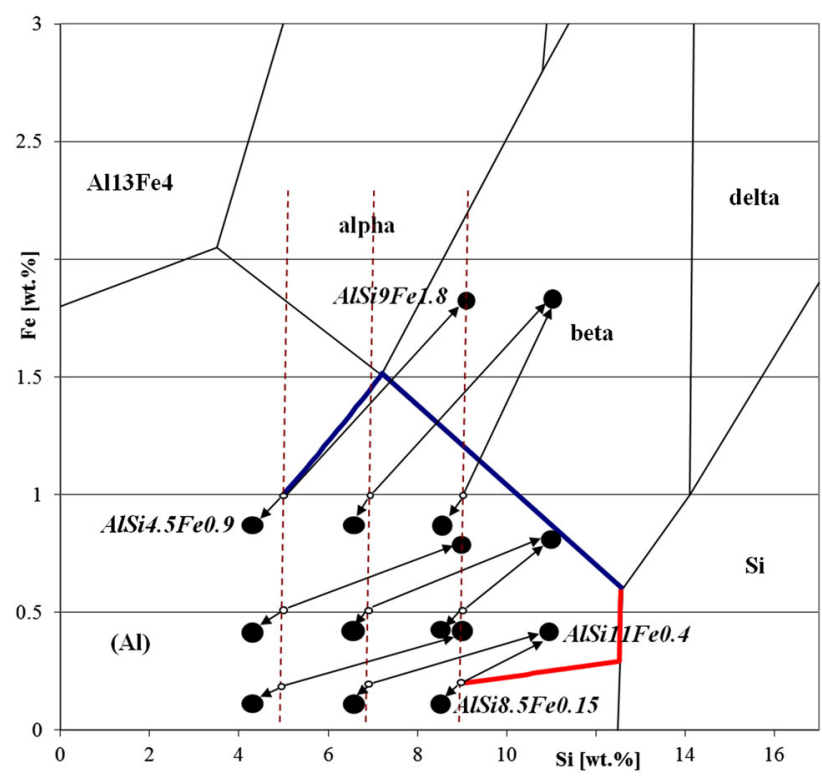

Fig. 4-Plot of the Al-rich corner of the liquidus projection of the Al-Fe-Si system. Filled black dots and black arrows represent the change in concentration of $\mathrm{Si}$ and $\mathrm{Fe}$ as a result of flow-induced segregation in the specimen center (increase in $\mathrm{Si}$ and $\mathrm{Fe}$ content, e.g., AlSi9Fe1.8 alloy) and in the outer dendritic ring (decrease in $\mathrm{Si}$ and $\mathrm{Fe}$ content, e.g., AlSi4.5Fe0.9 alloy). Small black circles represent the nominal concentrations of the studied AlSi5/7/9Fe0.2/0.5/1.0 alloys.

3D reconstructions encompassed cubes of $500 \times 500 \times 500 \mu \mathrm{m}$ for the region near the outer edge (area $A$ ) and the central part (area $D$ ), as presented in Figures 5 and 6 . Other interesting measurements originating from area $E$ (Figure 2) are demonstrated in Figures 7 through 14.

Figure 5(a) through (1) presents X-ray tomography pictures for the three Al-5 wt pet Si-0.2/0.5/1.0 wt pet $\mathrm{Fe}$ alloys solidified without and with fluid flow, taken in areas $A$ (the specimen edge) and $D$ (the specimen center). Figure 6(a) through (f) shows pictures for the three Al-7 wt pet $\mathrm{Si}-0.2 / 0.5 / 1.0$ wt pet Fe alloys in area $D$. In both figures, iron intermetallics appear with different shades of cyan whereas both the $\alpha$-Al phase and the AlSi eutectic are transparent. The $\mathrm{Fe}$ absorption for X-rays is significantly different from that of primary $\alpha-\mathrm{Al}$ and the eutectic; therefore, phases that contain $\mathrm{Fe}$ are clearly discernable. Visual accuracy is limited by the $1 \mu \mathrm{m}$ resolution obtained in the X-ray nanotom. The appearance of $\beta$ precipitates was also determined by the thickness of the platelets, which ranged from $0.5 \mu \mathrm{m}$ to $8 \mu \mathrm{m}$ (optical microscopy and SEM supported measurement).

Figures 5 and 6 clearly show an increase in number density and size of precipitated iron intermetallics along with the increase in the Fe content for Al-5 wt pct Si and Al-7 wt pet $\mathrm{Si}$ alloys respectively. The results for Al-9 wt pet Si-0.2/0.5/1.0 wt pet Fe alloys look similar to those for Al-7 wt pet Si-0.2/0.5/1.0 wt pet Fe and therefore are not presented here. X-ray tomography reconstructions indicate that iron intermetallics for the Al-5 wt pet Si-0.2 wt pet $\mathrm{Fe}$ are smaller and more 


\begin{tabular}{l|l|} 
area & Flow \\
& RMF \\
\hline
\end{tabular}

Fe 0.2

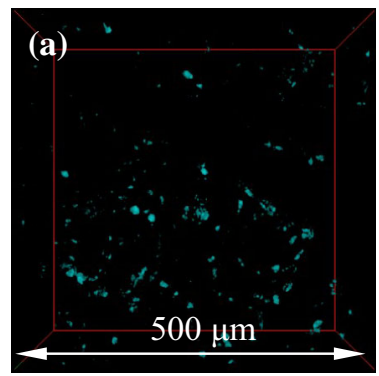

A

$0 \mathrm{mT}$

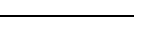

$6 \mathrm{mT}$
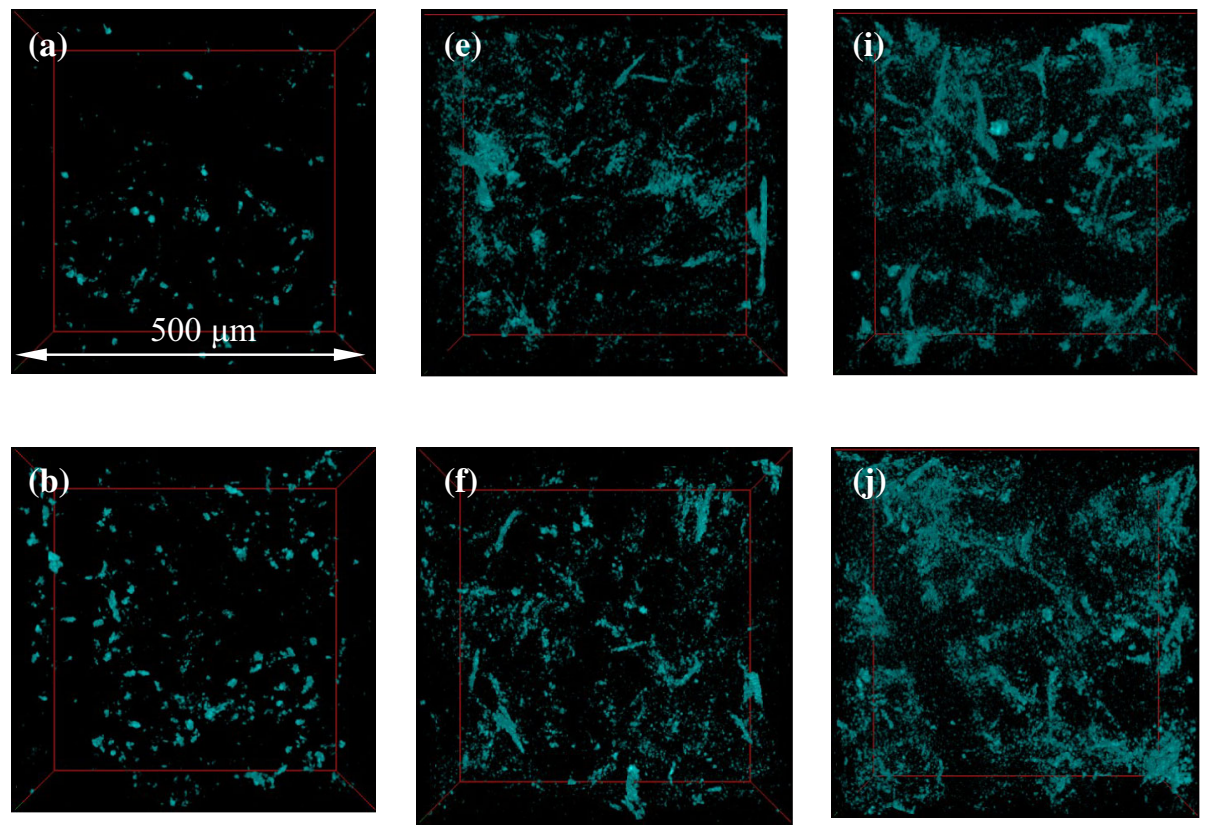

Fe 1.0
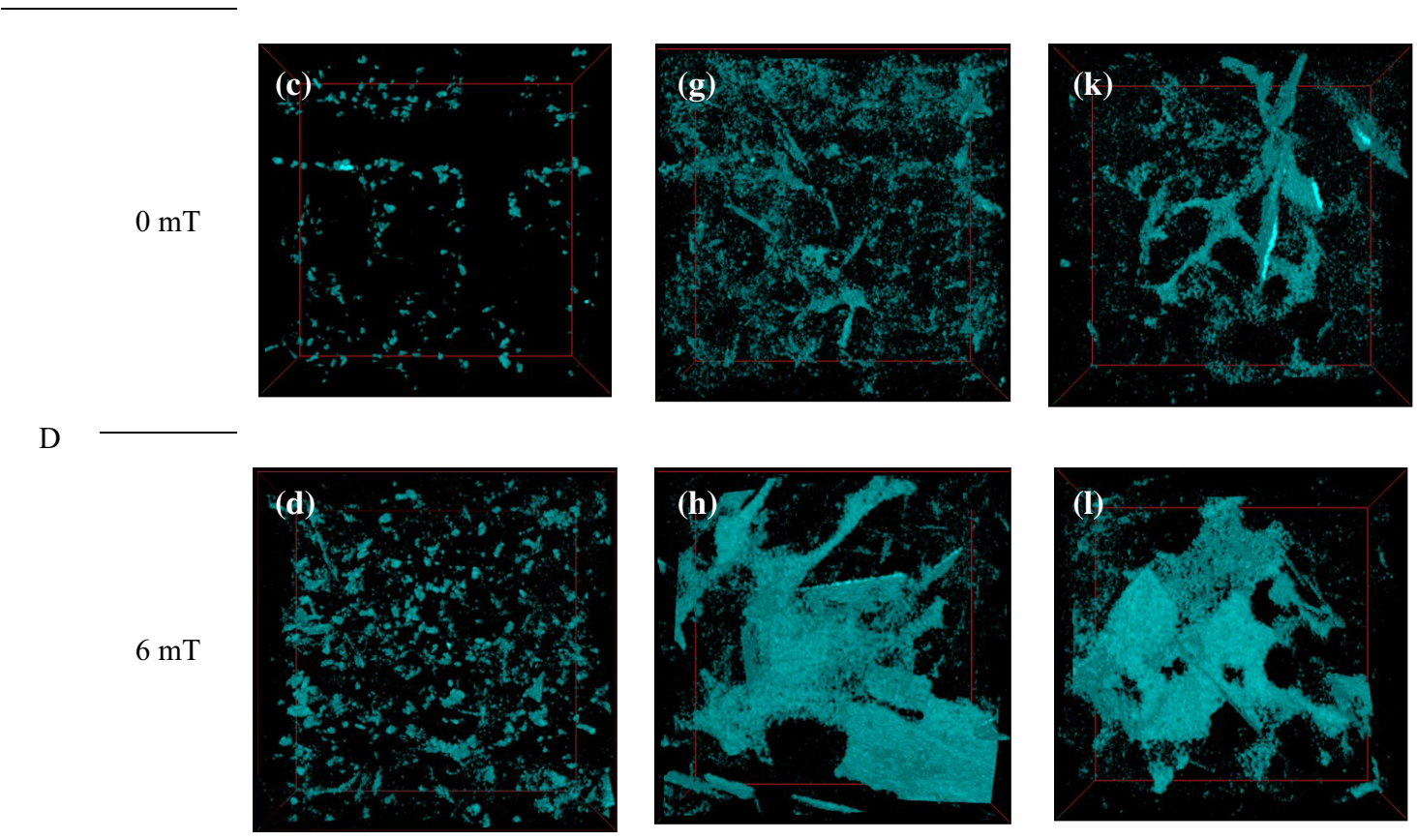

Fig. 5-3D X-ray microtomography of Al-5 wt pet Si-0.2/0.5/1.0 wt pet Fe alloys solidified without $(0 \mathrm{mT})$ and with $(6 \mathrm{mT})$ melt flow. Iron-rich intermetallics (in cyan) were found in the regions near the specimen edge (area $A$ ) and in the specimen center (area $D$ ) against the background of dendrites and eutectics (transparent). (For interpretation of the references to color in this figure legend, the reader is referred to the web version of this article.).

concentrated, their shape being neither a needle nor a platelet. The intermetallics of the Al-5 wt pct Si-0.5/ $1.0 \mathrm{wt}$ pct $\mathrm{Fe}$ alloys take the shape of platelets, which can best be seen in Figures 5(h) and (l). We can observe the distinctive diversification of $\beta-\mathrm{Al}_{5} \mathrm{FeSi}$ platelets occurring between $\mathrm{Al}-7$ wt pct $\mathrm{Si}-0.2 \mathrm{wt}$ pct $\mathrm{Fe}$ and Al-7 wt pet Si-0.5/1.0 wt pet Fe alloys (Figure 6). The $\mathrm{X}$-ray measurement of Al-7 wt pet Si-1.0 wt pet Fe shows formation of large $\beta-\mathrm{Al}_{5} \mathrm{FeSi}$ phases in the center (area $D$ ) of the sample; however, these platelets are not 


\begin{tabular}{l|l|} 
area & Flow \\
& RMF \\
\hline
\end{tabular}

Fe 0.2

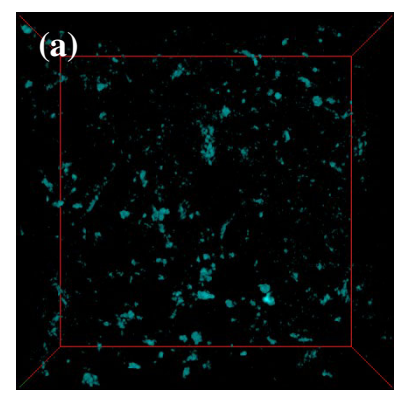

$\mathrm{D}$

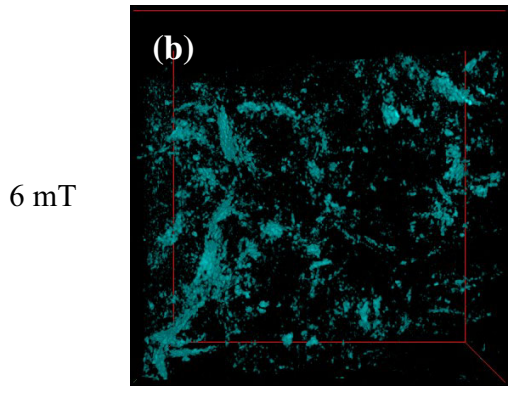

AlSi7 Fe0.2/0.5/1.0

Fe 0.5
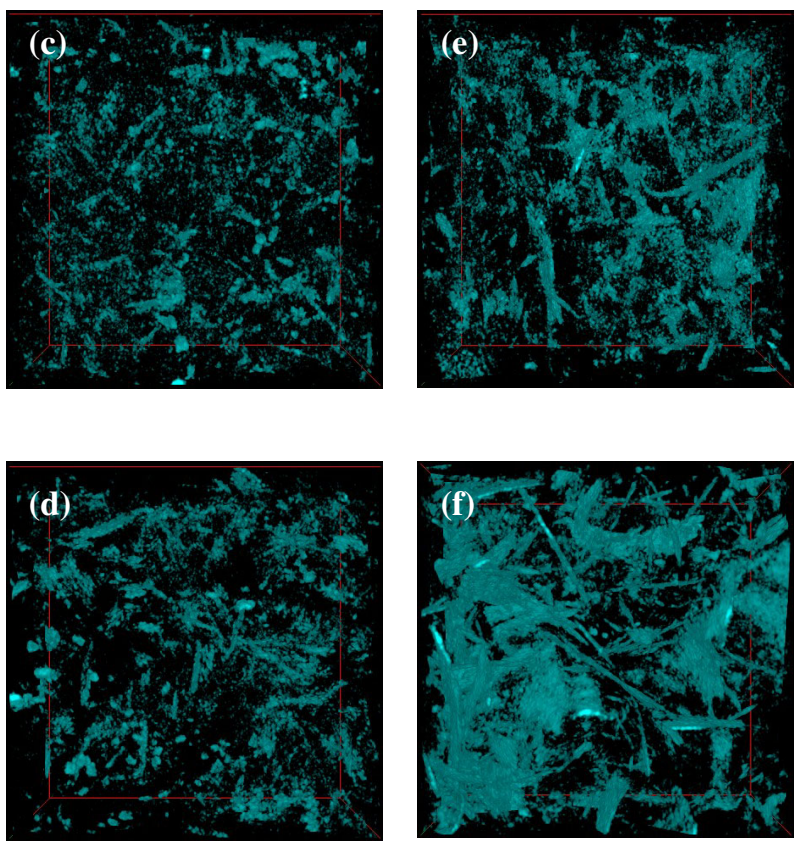

Fig. 6-3D X-ray microtomography of Al-7 wt pet Si-0.2/0.5/1.0 wt pet Fe alloys solidified without and with (6 mT) melt flow. Iron-rich intermetallics (in cyan) were found in the specimen center (area $D$ ) against the background of dendrites and eutectics (transparent). (For interpretation of the references to color in this figure legend, the reader is referred to the web version of this article.).

as large as in the case of the Al-5 wt pct $\mathrm{Si}-0.2 / 0.5 /$ $1.0 \mathrm{wt}$ pct $\mathrm{Fe}$ alloys. The effect of different $\mathrm{Si}$ and $\mathrm{Fe}$ concentrations is clearly visible.

The influence of fluid flow on the size of $\beta$ is hard to establish for area $A$ near the specimen edge in all alloys, but the number density increased under RMF (Figures 5(a), (b), (e), (f), (i), and (j)). The area $D$ (specimen center) for $\mathrm{Al}-5 \mathrm{wt}$ pct $\mathrm{Si}-0.5 / 1.0 \mathrm{wt}$ pct $\mathrm{Fe}$ alloys (Figures 5(g), (h), (k), and (1)) shows a clear melt flow effect: it has caused formation of large (about $500 \mu \mathrm{m}) \beta-\mathrm{Al}_{5} \mathrm{FeSi}$ particles, which occupy nearly the whole reconstructed cube $(500 \times 500 \times 500 \mu \mathrm{m})$. No large $\beta$ was formed in the Al-5 wt pct $\mathrm{Si}-0.2$ wt pet Fe alloy; however, the number density of intermetallics grew significantly, and in terms of qualitative evaluation, the size of iron intermetallics with melt flow in the specimen center (area $D$ ) expanded. The specimen Al-5 wt pet Si-1.0 wt pet Fe solidified without melt flow (area $D$, Figure $5(\mathrm{k})$ ) has an $\mathrm{Fe}$ concentration in the center of the specimen that is presumably so high that a big $\beta-\mathrm{Al}_{5} \mathrm{FeSi}$ platelet emerged therein; however, this was not as big as in the case of samples with fluid flow (Figures 5(h) and (1)). The influence of melt flow on $\beta$ phases is visible in area $D$ in the Al-7 wt pet $\mathrm{Si}-0.5 /$ $1.0 \mathrm{wt}$ pet $\mathrm{Fe}$ alloy specimens too, and qualitative estimates indicate that more intermetallics are present. The X-ray measurement of Al-7 wt pct Si-1.0 wt pet Fe shows formation of large $\beta-\mathrm{Al}_{5} \mathrm{FeSi}$ phases in the center of the sample (area $D$ ) under influence of fluid flow; however, these platelets are not as large as in the case of the Al-5 wt pet $\mathrm{Si}-0.2 / 0.5 / 1.0$ wt pet $\mathrm{Fe}$ alloys, where more intermetallics occurred and that took shape of platelets. The effect of melt flow is clearly visible.

The effect of the measurement area $A$ or $D$ is less visible than the effect of $\mathrm{Si}$ and $\mathrm{Fe}$ concentration and effect of fluid flow. The outer ring (area $A$ ) had small intermetallics, while in the center, they were larger and platelet shaped.

\section{3D Morphology of Fe-rich phases}

The $\beta-\mathrm{Al}_{5} \mathrm{FeSi}$ phases are most often called needles on 2D microsections, while they are referred to mostly as platelets in 3D geometry. The X-ray tomography results demonstrated Fe-rich phases with shapes different from simple forms such as needles or platelets. We observed (Figures 7 through 14 show reconstructions from area $E$, Figure 2) phases that are curved, bent, branched, crossing, hole-shaped, with imprints, wavy shapes, and formed around porosities.

The $\beta-\mathrm{Al}_{5} \mathrm{FeSi}$ intermetallics forming curved needles were observed on metallographic sections (Figure 7(a)). $\mathrm{X}$-ray tomography manifested the formation of around $300-\mu \mathrm{m}$-long and $4-\mu \mathrm{m}$-thick curved $\beta$ phases (Figure 7(b)) in the Al-7 wt pct Si-1.0 wt pct Fe sample solidified without fluid flow. Curvature of a $\beta-\mathrm{Al}_{5} \mathrm{FeSi}$ platelet can refer to the entire platelet (Figure 7(b)), which is evenly curved either along its entire length or in a particular place. 




(a)

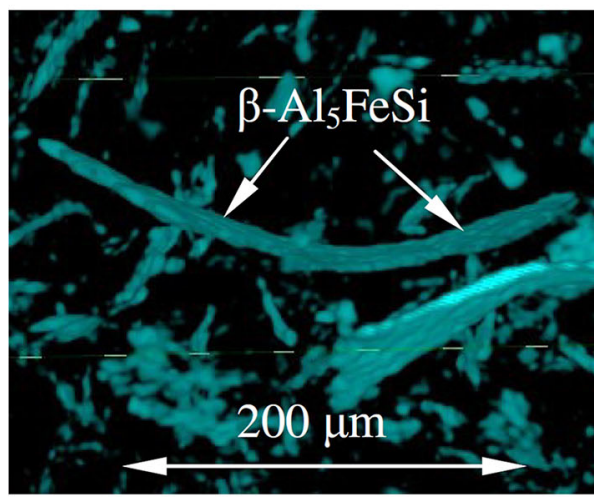

(b)

Fig. 7-SEM micrograph and 3D X-ray microtomography of the curved $\beta-\mathrm{Al}_{5} \mathrm{FeSi}$ (in cyan) in $\mathrm{Al}-5$ wt pct $\mathrm{Si}-1.0$ wt pet $\mathrm{Fe}$ alloy solidified with melt flow. $\alpha$-Al and eutectics are transparent.

Figure 8 shows a big $700 \mu \mathrm{m} \quad \beta-\mathrm{Al}_{5} \mathrm{FeSi}$ platelet, which is curved in a particular place, only along a short (about $100 \mu \mathrm{m}$ long) section (Figure 8 - the bending is marked by a white dotted line rectangle). Actually, this structure could be described as rectilinear but having a bent $\beta-\mathrm{Al}_{5} \mathrm{FeSi}$ with curvature in one part of one platelet. Figure 8 clearly shows bending of a continuous $\beta$ platelet and not a connecting point of two phases, which was analyzed in detail in $3 \mathrm{D}$ reconstructions.

The $\beta-\mathrm{Al}_{5} \mathrm{FeSi}$ intermetallics do not form straight platelets but instead show branched platelets (multibranch structures, Figure 7(a)) as seen in metallographic sections. Observations of metallographic specimens by optical microscopy showed, qualitatively, that the large $\beta$ platelets had fewer branches than was the case for smaller (up to $100 \mu \mathrm{m}$ long) $\beta$. Figure 9 shows an X-ray tomography 3D view of a branched $400-\mu$ m-long platelet. Here, the $\beta-\mathrm{Al}_{5} \mathrm{FeSi}$ platelet resembles a broken intermetallic because branching takes place near the precipitate edges. Figure 9(b) shows the platelet contact edges, where the branching process took place. Several platelets, which branch and cross one another, are also shown in the measurement cube in area $D$ (Figures 5(h), $(\mathrm{k})$, and (1)).

During growth (Figures 10(a), (b), and (c)), $\beta-\mathrm{Al}_{5} \mathrm{FeSi}$ intermetallics can cross each other: the process is definitely crossing and not branching. Crossing is clearly

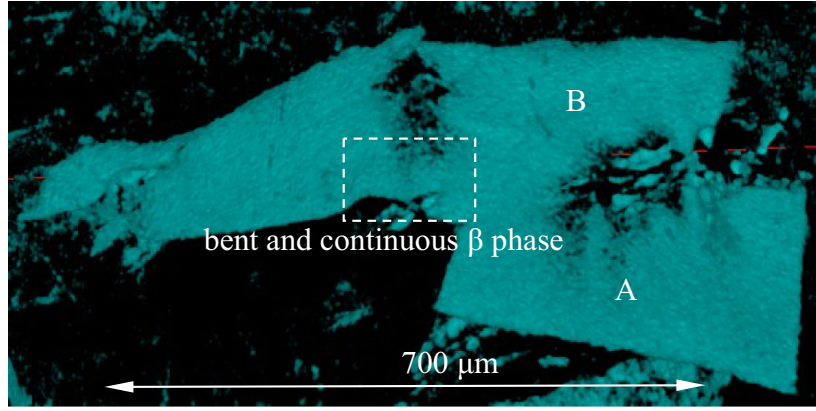

Fig. 8-3D X-ray microtomography of $\beta$ - $\mathrm{Al}_{5} \mathrm{FeSi}$ (in cyan) growing with twining (bent area) in Al-7 wt pet Si-1.0 wt pet Fe alloy solidified without melt flow. $\alpha-\mathrm{Al}$ and eutectics are transparent.

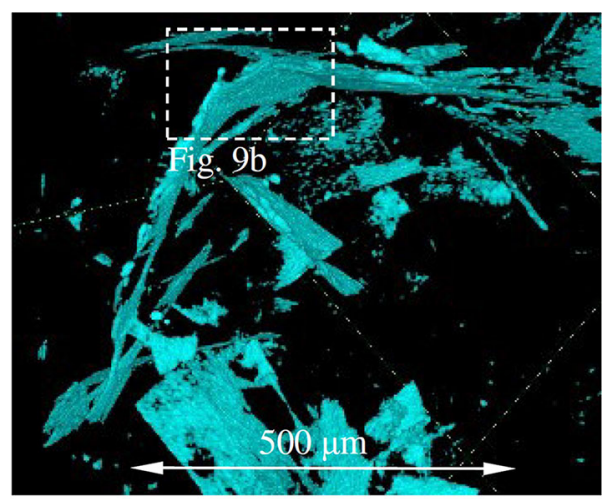

(a)

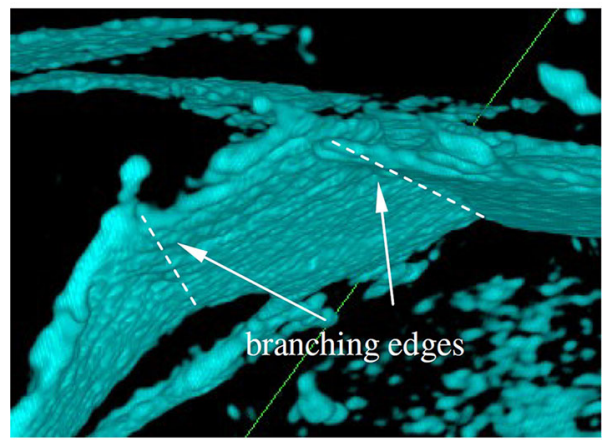

(b)

Fig. 9-SEM micrograph and 3D X-ray microtomography of the branched and hole-shaped $\beta-\mathrm{Al}_{5} \mathrm{FeSi}$ (in cyan) in Al-5 wt pct Si$1.0 \mathrm{wt}$ pct $\mathrm{Fe}$ alloy solidified with melt flow.

observed between platelets A and B in Figure 10(b), which shows that the profile of phase A after crossing platelet B is much less explicit, as if post-crossing growth is diminished. Both phases are located on the melt-pore surface, and the platelets parts, after crossing, immersed into the melt.

The hole-shaped edges of many $\beta$ phases reflect dendrites, and the characteristic dendritic shape can be located on the inner or the outer edge of $\beta$ platelet (Figures 2(h), (1), 10(c), 11). In the case of inner edges, the hole-shaped $\beta-\mathrm{Al}_{5} \mathrm{FeSi}$ phase grew precisely around the dendrite (Figure 11) and was most probably tightly attached to it. Figure 11 shows $\beta-\mathrm{Al}_{5} \mathrm{FeSi}$ outer edges 


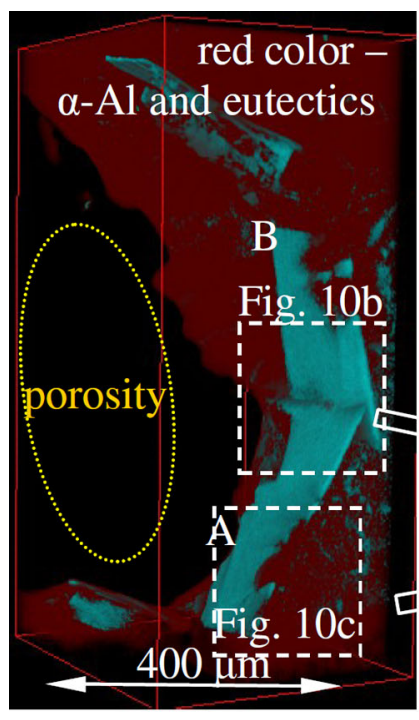

(a)

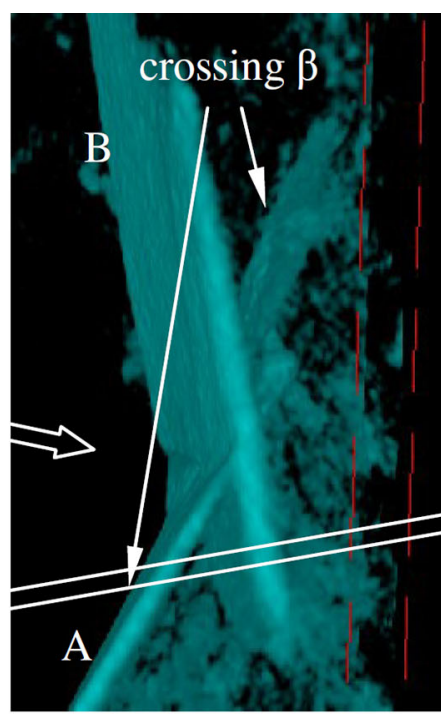

(b)

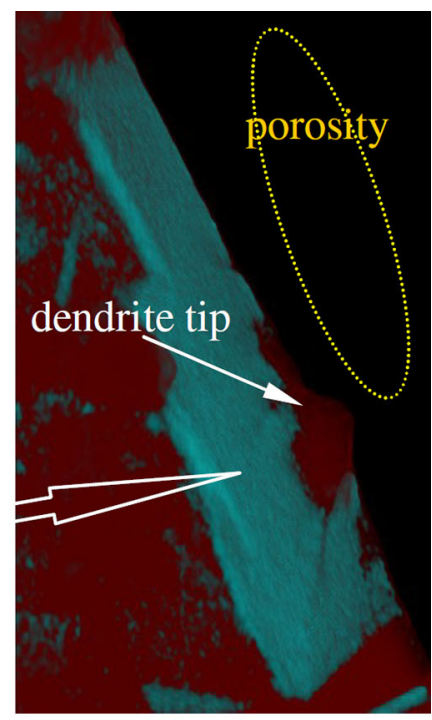

(c)

Fig. 10-3D X-ray microtomography of the crossing $\beta$-Al5FeSi phases localized near porosity (in cyan) $\mu$ m in Al-7 wt pct Si-1.0 wt pct Fe alloy solidified without melt flow. Shown are intermetallics (in cyan), porosity (pointed with yellow ellipses and transparent), and $\alpha$-Al and eutectics in red $(a, c)$ or transparent $(b)$. (For interpretation of the references to color in this figure legend, the reader is referred to the web version of this article.).

shaped by dendrites. Figure 10(c) demonstrates an example of $\beta$ growing on the melt-gas interface around the dendrite tip, which has grown from the melt and reached the melt-gas interface. The $2 \mathrm{D}$ microstructures (Figure 11(c)) show $\beta$ - $\mathrm{Al}_{5} \mathrm{FeSi}$ needles that sometimes look like shorter collinear intermetallics separated by dendrites or eutectics, in which circumstance, they likely constitute a part of the same hole-shaped platelet. The A1Si5 alloy solidified without melt flow (Figure 5(k)) displayed a $\beta-\mathrm{Al}_{5} \mathrm{FeSi}$ platelet that also shows significant traces of dendrites as by fluid flow, meaning a lack of segregation in the central part of the specimen. Melt flow-solidified structures (Figures 5(h) and (1)) contain $\beta$, which also bears traces of dendrites; however, these traces are much smaller (in comparison with specimen solidified without flow), which confirms the existence of the eutectic center and segregation of alloying elements.

Figure 12 shows $\beta$ - $\mathrm{Al}_{5} \mathrm{FeSi}$ with imprints, where the surface is not flat and the edges are not straight. The platelet surface shows valleys and hills, and the edges present holes (as previously seen on Figures 2(h), (1), 9(c), and 10). The distances between imprinted consecutive hills (or consecutive valleys) and between holes were about $100 \mu \mathrm{m}$ and correspond to SDAS for those alloys. ${ }^{[31]}$ The valleys perfectly correspond to the holes at the precipitate's left edge (Figure 12) with similar distances (about $100 \mu \mathrm{m}$ ) between them. The holes formed along the edge outline the dendrite forms. The opposite side of $\beta$ (not presented on in Figure 12) shows only one valley located by the middle hole (one of the five holes) and it is not clearly shaped valley, but some irregular surface.

Figure 13 shows wavy-shaped $\beta$ phases similar to intermetallics with imprints, but this time, the distances between hills and between valleys are about $50 \mu \mathrm{m}$ and they are the same on both opposite sides of $\beta$ and looked as reflected - the hills on one side reflects hills on the opposite side. In this case, the thickness of the $\beta$ precipitate varies along the platelet. Figures 13(b) and (c) show the same $\beta$ precipitate but with changed intensity (visibility) gained from X-ray tomography and emphasized the changes in its thickness. Black arrows showed the places for valleys detected on Figure 13(a).

$\mathrm{X}$-ray tomography also showed the formation of $\beta$ around porosity. The Al-7 wt pet Si-1.0 wt pet Fe alloy solidified without melt stirring (RMF $0 \mathrm{mT}$ ) contained a large porosity located in the center of the 8-mm-diameter specimen (Figure 14), with the pore size reaching up to $1500 \mu \mathrm{m}$ in diameter. On Figure 14(a), cyan represents intermetallics, black areas marked with yellow ellipses depict porosity, and $\alpha-\mathrm{Al}$ and eutectics are transparent. The melt-gas surface built by the porosity showed formation of $\beta-\mathrm{Al}_{5} \mathrm{FeSi}$ intermetallics and their specific feature is that they are positioned precisely on the melt-gas interface (Figure 14), parallel to the surface and not inclined at an angle. Figure 14(b) shows the same projection of porosity as seen in Figure 14(a), but with alloy marked in red, porosity as transparent, and intermetallics in cyan. $\beta$ $\mathrm{Al}_{5} \mathrm{FeSi}$ formed around porosity belongs to one of bigger $\beta$ detected in all 18 specimens studied and their lengths range from 400 to $700 \mu \mathrm{m}$. Phase A depicted in Figure 10 (and Figure 14) indicates a propeller-like twist situated precisely on a porosity surface and interacting with a dendrite tip (Figure 10(c)). The observed platelet A (Figures 10(a) through (c)) ends its growth after crossing B, and going deeper into melt disappears.

\section{DISCUSSION}

The results shown for X-ray tomography on the effect of fluid flow and 3D morphology of $\beta$ phases, and the 


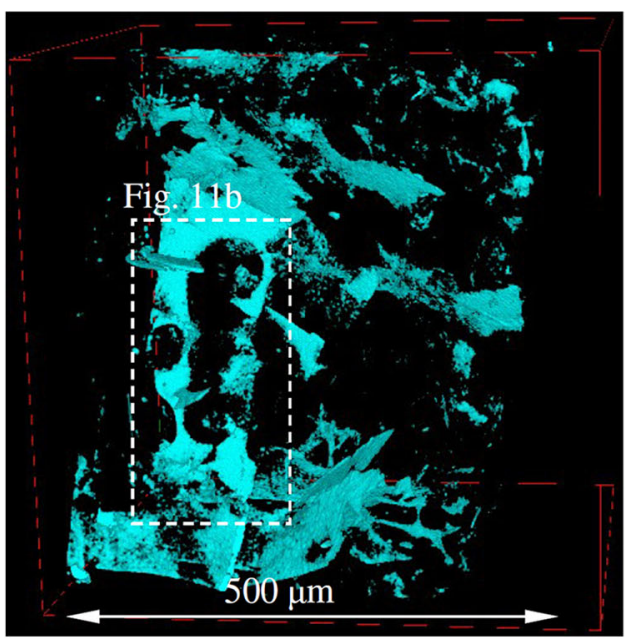

(a)

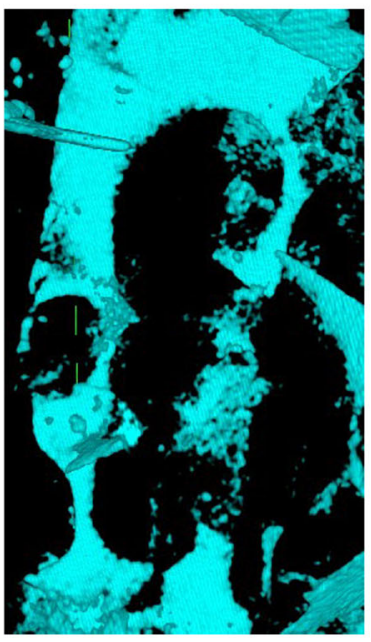

(b)

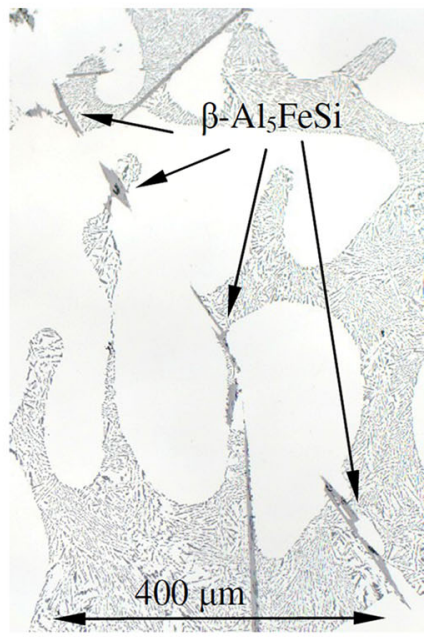

(c)
Fig. $11-(a, b) 3 \mathrm{D}$ X-ray microtomography of the hole-shaped $\beta$ - $\mathrm{Al}_{5}$. FeSi (in cyan) in Al-5 wt pct Si-1.0 wt pct Fe alloy solidified with melt flow. $\alpha$-Al and eutectics are transparent. (c) 2D optical micrograph of collinear parts of one the same long $\beta$ phase (dark gray color).

reasons for the various shapes found, require some discussion. For the 3D distribution and shapes of $\beta$ phases, studying the morphology of the specimens by growth of $\beta$ and also by the melt flow occurred in specimens. The phenomena of lengthening and shortening of $\beta$ phases as interplay between flow and formed phases should also be analyzed.

\section{A. Effect of Fluid Flow and Alloy Composition on Microstructure}

The X-ray tomography in the outer specimen ring (area $A$ ) showed that the influence of fluid flow on length of $\beta$ is hard to establish for all alloys, but the number density of $\beta$ clearly increased under RMF (Figures 5(a), (b), (e), (f), (i), (j) and 6). The present study is the first to show the effect of fluid flow on the number density using $\mathrm{X}$-ray tomography, and the results are in agreement

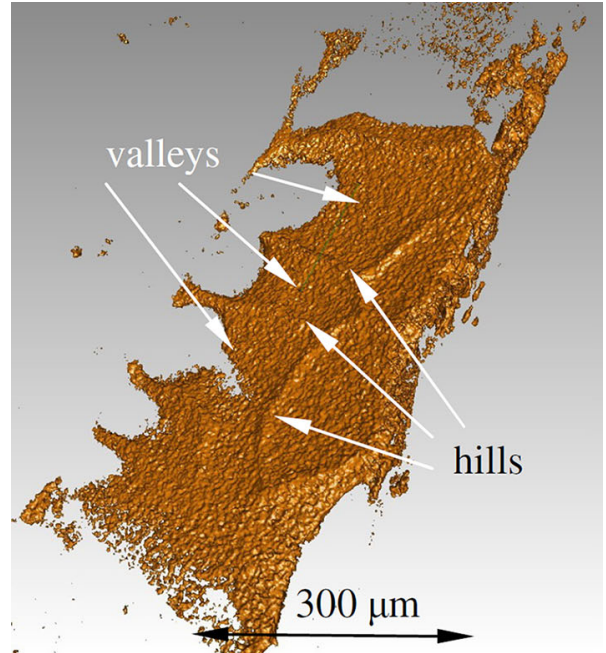

(a)

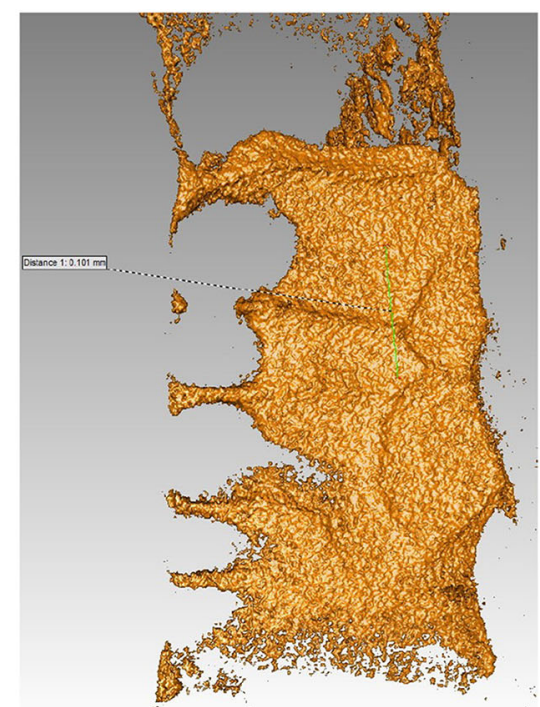

(b)

Fig. 12-Two projections of the same $\beta$ - $\mathrm{Al}_{5} \mathrm{FeSi}$ phases (in yellow) with imprints on the surface in Al-7 wt pct Si-1.0 wt pct Fe alloy solidified without melt flow. $\alpha-\mathrm{Al}$ and eutectics are transparent.

with those from earlier studies ${ }^{[30]}$ conducted on 2D microstructures. Figures 5 and 6 show that the density of intermetallics in the specimen center (area $D$ ) is slightly higher than on the outside (area $A$ ). The results of X-ray tomography are compliant with the course of number density $n_{\beta}$ at the specimen cross section in Reference 30 where $n_{\beta}$ increases from the specimen edge to the center. 2D metallographic ${ }^{[30]}$ reveled that $n_{\beta}$ increases from $460 \mathrm{~mm}^{-2}$ in area $A$ to $534 \mathrm{~mm}^{-2}$ in area $D$ for solidification without melt flow (without RMF), and for solidification with melt flow (RMF), $n_{\beta}$ increases from $614 \mathrm{~mm}^{-2}$ in area $A$ to $1633 \mathrm{~mm}^{-2}$ in area $D$ for AlSi5Fe1.0 alloy. More general results for all AlSi5/7/ $9 \mathrm{Fe} 0.2 / 0.5 / 1.0$ studied alloys presented increase in number density $n_{\beta}$ from 370 to $576 \mathrm{~mm}^{-2}$ without melt flow (RMF) and from 433 to $820 \mathrm{~mm}^{-2}$ for solidification with RMF. 


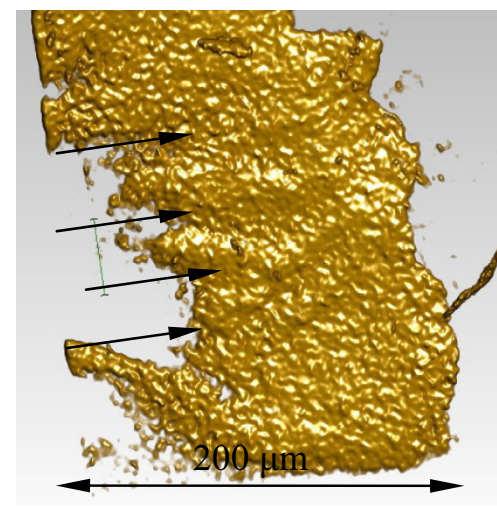

(a)

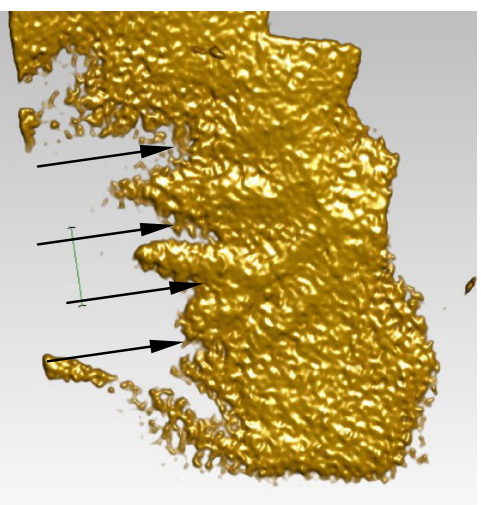

(b)

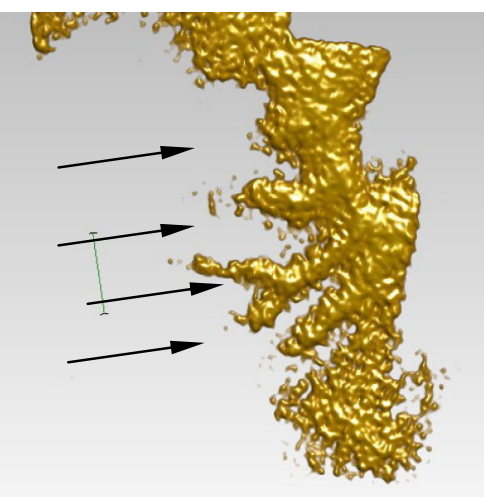

(c)

Fig. 13-3D X-ray microtomography of the $\beta$-Al5FeSi (in cyan) with traces of instability in Al-7 wt pct Si-1.0 wt pct Fe alloy solidified without melt flow. Black arrows show places for valleys found. (For interpretation of the references to color in this figure legend, the reader is referred to the web version of this article.).

Area $D$ (specimen center) for $\mathrm{Al}-5 \mathrm{wt}$ pct $\mathrm{Si}-0.5 /$ 1.0 wt pct Fe alloys (Figures 5(g), (h), (k), and (1)) shows a clear melt flow effect: the valuable X-ray tomography images showed that stirring caused formation of large (about $500 \mu \mathrm{m}) \beta-\mathrm{Al}_{5} \mathrm{FeSi}$ particles, which occupy nearly the whole reconstructed cube. This contrasts to the findings in Reference 30, where the specimen center increased in number density $n_{\beta}$ (from 534 to $1633 \mathrm{~mm}^{-2}$ for AlSi5Fe1.0 alloy), and only a very small increase was noted in the length of $\beta$ platelets. The melt flow caused decrease in the length $L_{\beta}$ from 25.7 to $20.8 \mu \mathrm{m}$ in dendritic area $A$ and slight increase from 19.4 to $19.9 \mu \mathrm{m}$. More general results for all $\mathrm{AlSi} 5 / 7 / 9 \mathrm{Fe} 0.2 /$ $0.5 / 1.0$ studied alloys presented that melt flow decreases length $L_{\beta}$ from 23.3 to $18.9 \mu \mathrm{m}$ in dendritic area $A$ and increases from 17.7 to $19.3 \mu \mathrm{m}$ in eutectic specimen center $(\operatorname{area} D)$. The study ${ }^{[30]}$ on $2 \mathrm{D}$ microstructure did not document the large intermetallics (e.g., as seen in Figures 5(h), (k), and (l)). The fluid flow effect on the microstructure of the Al-5/7 wt pet Si-0.2/0.5/1.0 wt pet $\mathrm{Fe}$ alloys is also clear in the X-ray tomography results, in agreement with earlier research, ${ }^{[25]}$ where Steinbach reveled the appearance of a center enriched in $\mathrm{Si}$ and $\mathrm{Fe}$ in 2D microsections of samples solidified under the influence of melt flow (RMF). The current study and ${ }^{[26,27]}$ revealed larger $\beta$-phase particles in the center, but only 3D X-ray visualization verified an increased number density of intermetallics. The X-ray investigations presented here provide new views on the effect of fluid flow and help to fill the gap between results. ${ }^{[26,27,30]}$ In,${ }^{[26,27]}$ Steinbach confirmed the appearance of a center enriched in $\mathrm{Si}$ and $\mathrm{Fe}$ in samples solidified under the influence of melt flow (RMF) as a consequence of segregation the dendrite free area, where the sample center showed formation of longer $\beta$ platelets, with an increase in length from about 150 to $250 \mu \mathrm{m}$. By contrast, in Reference 30, flow was indicated as the cause of increased number density $n_{\beta}$ from 600 to $800 \mathrm{~mm}^{-2}$ (Figure 17 and 18 in Reference 30) and only a small increase in length $L_{\beta}$ from 17.7 to $19.3 \mu \mathrm{m}$ (Figure 13 in Reference 30 for AlSi5Fe1.0) in the enriched specimen center. Histograms of metallographic sections in Reference 30 displayed large numbers of small $\beta-\mathrm{Al}_{5} \mathrm{FeSi}$ platelets with lengths of about 5 to $50 \mu \mathrm{m}$ and also the occurrence of platelets about $200 \mu \mathrm{m}$ long.

The quality of X-ray results does not allow for quantitative confirmation of the outcome related to the average length of $\beta-\mathrm{Al}_{5} \mathrm{FeSi}$ platelets or the number density measured in Reference 30, but it confirmed qualitatively the increase in number density. The present study linked the results from both ${ }^{[26,27,30]}$ and proved that fluid flow can increase the length of $\beta$ even more strongly, to about $500 \mu \mathrm{m}$ (Figures 5(h), (k), and (l)) or more (Figures 7 through 14). In addition, flow can increase the number density of intermetallics in the dendritic area $A$ and in the eutectic center when observed only on 2D microstructures without 3D tomography. X-ray tomography showed that flow can increase the number density and can cause formation of large intermetallics that can form complicated structures (Figures 10 through 14) and disclosed the 3D distribution of $\beta$.

The measurements for Al-5/7/9 wt pct Si-0.2/0.5/ $1.0 \mathrm{wt}$ pct $\mathrm{Fe}$ alloy imply that the X-ray tomography is successful at detecting intermetallics if they are big enough. X-ray tomography investigation is efficient and exposed large (over $1-\mu \mathrm{m}$ thick) $\beta-\mathrm{Al}_{5} \mathrm{FeSi}$ phases which lie deep in the specimen and cannot be seen on microstructures through either optical microscope or SEM. The real size (length) of the platelets can only be measured in $3 \mathrm{D}$ geometry.

The studies ${ }^{[30]}$ revealed shortening of $\beta-\mathrm{Al}_{5} \mathrm{FeSi}$ phases under influence of melt flow: this was more effective than decreasing Fe concentration (from $1.0 \mathrm{pct}$ in AlSi5Fe1.0 to 0.2 in AlSi5Fe0.2 alloy). An increase in the number density of the needles was also observed. The Fe-rich $\beta$ phases shaped as long and thin platelets grew as faceted plates due to the large entropy of fusion (about $4.97 \mathrm{~J} / \mathrm{mol} \mathrm{K}) \cdot{ }^{[33]}$ According to Fang, ${ }^{[34]}$ formation of $\beta$ phases occurs largely due to significantly different solid-liquid interface energy and associated disparity in growth rates along different crystallographic directions. The shortening of average length $L_{\beta}$ (Fig- 


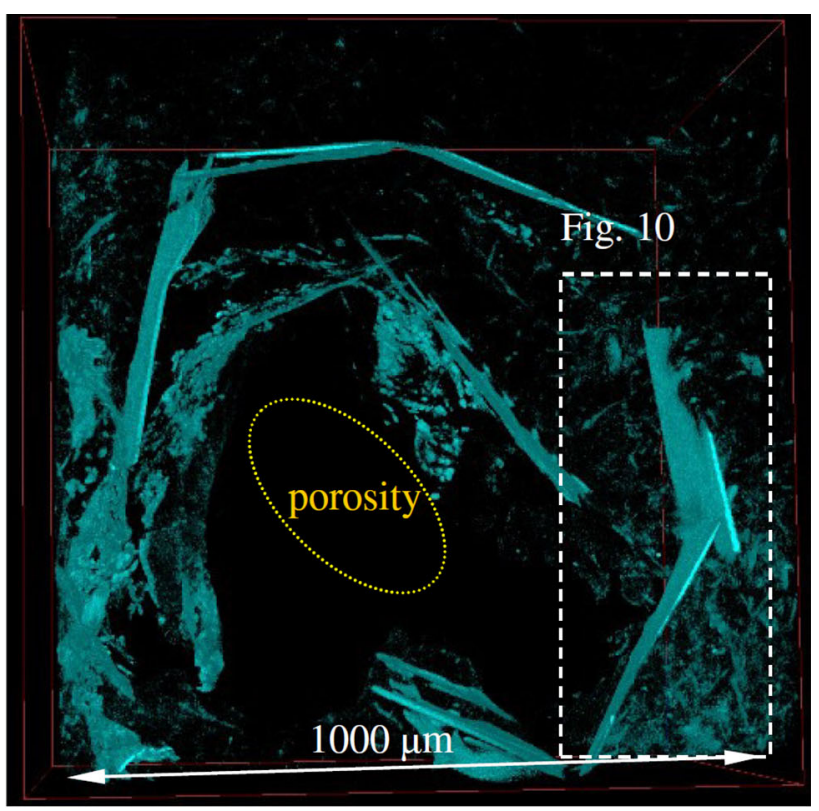

(a)

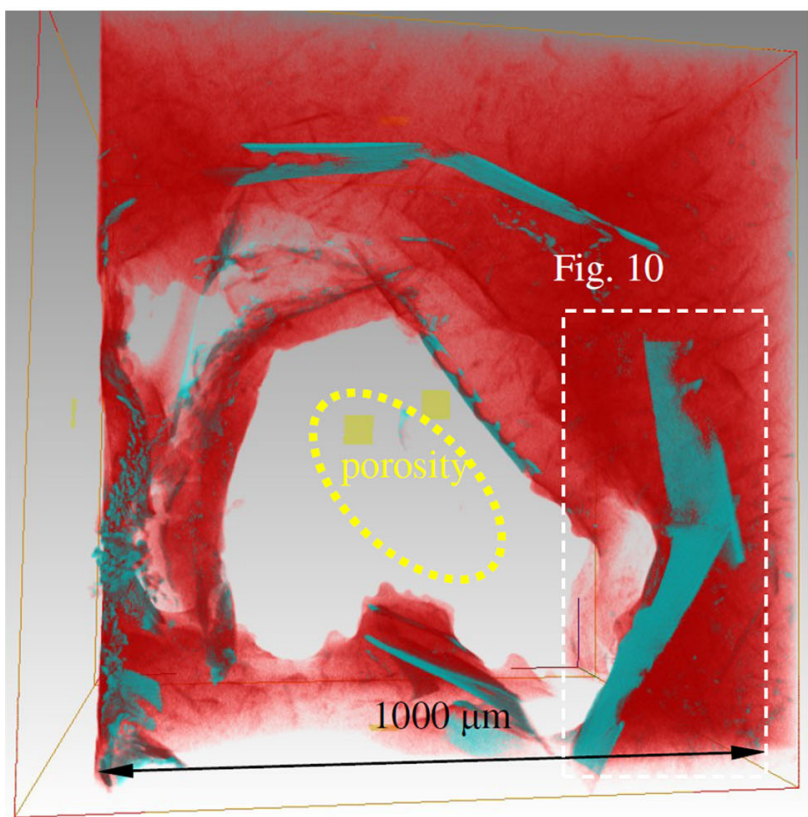

(b)

Fig. 14-Two views of the same group of $\beta$-A15FeSi phases (in cyan) located near porosity (transparent-pointed with ellipse) and on the interface melt-gas in Al-7 wt pet $\mathrm{Si}-1.0 \mathrm{wt}$ pet $\mathrm{Fe}$ alloy solidified without melt flow. $\alpha$-Al dendrites and eutectics shown as $(a)$ transparent, $(b)$ in red color. (For interpretation of the references to color in this figure legend, the reader is referred to the web version of this article.).

ure 10 through 13) suggests that melt shearing could reduce the difference in $\mathrm{S}-\mathrm{L}$ interfacial energies and in turn slow down preferential growth in the direction of the longitudinal layer axis. ${ }^{[34]}$ This could occur due to the reduction in the diffusion layer thickness at the S-L interface and a disturbance of local equilibrium ahead of the growing solidification front. ${ }^{[34]} \mathrm{Nafisi}^{[35]}$ discussed this idea and concluded that forced flow effect on the $\beta$ needles might mainly be due to mechanical or thermomechanical fragmentation of dendrites and creation of multiple nucleants within the bulk.

\section{3D morphology of Fe-rich phases}

The $\beta-\mathrm{Al}_{5} \mathrm{FeSi}$ phases recognized as needles in $2 \mathrm{D}$ microsections and platelets in $3 \mathrm{D}$ geometry in recent work seem to take on more complicated shapes. Fephases (Figures 7 through 14) appeared as curved, bent with twining, branched, crossing, hole-shaped, with imprints, wavy shapes and formed around porosities.

Earlier studies ${ }^{[30-32]}$ conducted on metallographic specimens analyzed the occurrence of 10 to $50-\mu \mathrm{m}-1$ long thin curved precipitates (Figure 4(a)); however, curved $\beta$ longer than $100 \mu \mathrm{m}$ has never been detected. A presumption in References 30, 31 was that melt flow might bend intermetallics, and the influence of the melt flow based on measurement of number density of curved phases was also analyzed. The number density of curved phases for the alloys studied was 30 to $160 \mathrm{~mm}^{-2}$. The results did not reveal any correlation between the number density of the curved phases with the melt stirring, iron concentration, or localization inside the specimens. In Reference $16, \beta-\mathrm{Al}_{5} \mathrm{FeSi}$ needles were detected, which at the beginning of their growth deform under reciprocal interaction with the neighboring $\beta$ platelets, oxide skins, and surrounding dendrites. After that, during growth and thickening, the needles gradually straighten.

In the first stage of growth, the $\beta-\mathrm{Al}_{5} \mathrm{FeSi}$ phases are supposedly elastic enough to bend not only as a result of interaction with dendrites and oxides, but also under the influence of forced flow. Since numerous curved phases, both thin and thick, have been observed, the thickening followed by the straightening process does not occur in all platelets. Most probably, interactions that shaped $\beta$ - $\mathrm{Al}_{5} \mathrm{FeSi}$ platelets in a curved solidified form either did not disappear during solidification or were significant enough to resist the phase's tendency to straighten during growth, which occurred in both small and large platelets with lengths up to $300 \mu \mathrm{m}$. The $\beta$ with the greatest curvature was formed in interaction with dendrites or other phases, and the curvature did not result from melt stirring. We therefore are led to suppose that the solute pile-up of $\mathrm{Si}$ and $\mathrm{Fe}$ at the $\alpha$-dendrite interface allows nucleation and growth of $\beta$ in the form of curved plates. Small $\beta$-particles could also presumably be shifted by the dendrite interface, as was reported for AlSiMn by Hecht. ${ }^{[36]}$

Deformations of intermetallics (e.g., loss of their plate-like form) as in curved phases (Figure 7) can be caused by constantly growing dendrites and their secondary and tertiary arms. $\beta$ precipitates are relatively large and thick; therefore, the bending relates to large phases, and the forces driving the process are likely to be strong with regard to this process scale. The bending can be in a particular place, rather than along the whole platelet (Figure 8), so the deformation can also be caused by twining occurring during growth.

The current literature lacks data about the number density of branched phases (Figure 9), and only Pun- 
creobutr $^{[19]}$ estimated branching as 37 pct of observed interactions between platelets. Earlier investigations ${ }^{[30]}$ did not analyze the number density of branched phases with respect to fluid flow. The branching angle has not been ascribed any particular value, and according to, ${ }^{[16,19]}$ branching may occur at various angles.

Some platelets formed crossing structures (Figure 10). Platelet A, after crossing platelet B, is much less explicit, as if post-crossing growth diminished. After crossing, the part of the platelets immersed in the melt disappeared, perhaps due to the lower $\mathrm{Fe}$ concentration. Supposedly, in the case of crossing, each of $\beta-\mathrm{Al}_{5} \mathrm{FeSi}$ phases nucleated separately and crossed each other during growth, in a different manner than occurs in branching. Again, the current literature lacks data regarding the number density or length of crossing phases and its relation to fluid flow or chemical composition.

Hole-shaped $\beta$ intermetallics occurred in nearly all the current studied specimens (Figures 11, 5(h) and (1)) and earlier one. ${ }^{[37]}$ Wang $^{[33]}$ claimed that the first-stage lateral growth of $\beta-\mathrm{Al}_{5} \mathrm{FeSi}$ ceases at the point when the rapidly expanding $\beta$ impinges the surrounding primary phase dendrite. Terzi et al., ${ }^{[16]}$ following Wang, ${ }^{[33]}$ claimed that plates grow quickly until they impinge on a dendrite or obstacle. They then begin to thicken at a low growth rate. Once the obstacle (dendrite) is passed, $\beta$ can grow quickly again by lateral growth until the next impingement with an obstacle. Lateral growth is probably quick, and the movement of the precipitate edge is smooth. The rectangular (a very thin cube) outline of the $\beta-\mathrm{Al}_{5} \mathrm{FeSi}$ phase shape would be determined first, with a more or less constant velocity. In the presence of dendrites, the cessation of growth seems to be caused by dendritic obstacles, but in the absence of primary $\alpha-\mathrm{Al}$, another factor must be determining the end of lateral growth (e.g., to low a $\mathrm{Fe}$ content in neighborhood of $\beta$ ). The $\beta$ - $\mathrm{Al}_{5} \mathrm{FeSi}$ can be assumed to form as defect free platelets (well-shaped rectangles or very thin cubes without holes) only when they are small and have grown in the eutectic areas far away from dendrites. Most often, they are hole-shaped in three-dimensional visualization, while they appear as collinear separated needles in 2D microsections (Figure 11(c)).

The observed platelets with imprints on the surface (Figure 12) showed that the distances between hills correlated to SDAS. Once nucleated, the $\beta$ platelets grow with a very high speed, observed to be about $100 \mu \mathrm{m} / \mathrm{s}^{[33]}$ The growth is at first very rapid, mostly at the edges of the platelets, where attachment of atoms is most favorable. The lateral growth of the four $\beta$ platelets studied in Reference 33 showed an average velocity of $32 \pm 20 \mu \mathrm{m} / \mathrm{s}$ and maximum of $100 \mu \mathrm{m} / \mathrm{s}$. In Reference 16 , the lateral growth of $\beta$ platelets showed a maximum recorded rate of $750 \mu \mathrm{m} / \mathrm{min}(12.5 \mu \mathrm{m} / \mathrm{s})$. The lateral initial growth velocity was measured 24 to $31 \mu \mathrm{m} / \mathrm{s}$ in Reference 19 and after that first stage it decreased, and the mean growth velocity of the whole platelet was in the range 1 to $2 \mu \mathrm{m} / \mathrm{s}$. In the second stage of the growth, the $\beta$ platelets grow by thickening, i.e., by expanding in a less favorable growth direction normal to the faces of the $\beta$ phases. These intermetallics grow quicker in length and much slower in thickness, $2 \mu \mathrm{m} /$ $\min =0.03 \mu \mathrm{m} / \mathrm{s}^{[17]}$ or $0.033 \mu \mathrm{m} / \mathrm{s}^{[19]}$

In our experiments, the solidification velocity was $40 \mu \mathrm{m} / \mathrm{s}$. When considering the length $150 \mu \mathrm{m}$ of $\beta-\mathrm{Al}_{5} \mathrm{FeSi}$ and average growth velocity $32 \pm 20 \mu \mathrm{m} / \mathrm{s}$, we obtain a growth time of 4.3 seconds. Similarly, for shorter platelets $(30 \mu \mathrm{m})$ and the maximum recorded velocity $(100 \mu \mathrm{m} / \mathrm{s})$, the growth might proceed to 0.3 second, but the thickening lasts much longer. Therefore, growth in length is a very fast process, and may occur very suddenly when enough space is available between dendrites, but thickening occurs slowly and gradually between formed primary $\alpha-\mathrm{Al}$ and can cause dendrite-shaped imprints on the surfaces of the platelets.

The existing literature lacks data on $\beta$ platelets with imprints, where the hills on one side reflect hills on the opposite side (Figure 13), and the distances between hills or between valleys and between valleys do not correspond to SDAS. The $\beta$ precipitate growth appears to form wavy patterns perhaps caused by kind of instabilities on the surface during thickening.

The size and number density of $\beta$ platelets depend on the chemical composition of the alloy, solidification conditions, etc., and earlier studies provide examples of $\beta$ with sizes of $10,{ }^{[38]} 15,{ }^{[39]} 75,{ }^{[34]} 150,{ }^{[33]} 250,{ }^{[26,27]} 400,{ }^{[15]}$ $500,{ }^{[16]} 1000,{ }^{[19]}$ and $5-250^{[30]} \mu \mathrm{m}$. In the current study, the largest observed platelet was $1300-\mu \mathrm{m}$ long, which means that X-ray tomography is more efficient at showing the real sizes of $\beta$ compared to $2 \mathrm{D}$ microsections.

$\beta$ - $\mathrm{Al}_{5} \mathrm{FeSi}$ precipitates formed around porosities (Figure 14) belonging to one of larger $\beta$ intermetallics detected in all 18 specimens studied; their lengths ranged from 400 to $700 \mu \mathrm{m}$. Terzi, ${ }^{[16]}$ using X-ray technique, observed that $\beta$ intermetallics are initiated at or near the surface of the sample fully surrounded by oxide. Before the A1Si eutectic period, ${ }^{[16]}$ only four nucleation and growth events occurred for the $\beta$ phases, and no independent nucleation of $\beta-\mathrm{Al}_{5} \mathrm{FeSi}$ was observed within the bulk liquid during solidification of the sample. All $\beta$ intermetallics initiated at the surface and these grew and branched.

Two mechanisms have been proposed for $\beta-\mathrm{Al}_{5} \mathrm{FeSi}$ nucleation, on small entrained oxide films ${ }^{[16,40,41]}$ and nucleation on AlP nucleant particles. ${ }^{[42,43]}$ The outer interfaces of oxide films appear to act as preferred substrates for the nucleation and growth of some Ferich phases, especially $\beta$ phases along oxide films. ${ }^{[4,44]}$ Good atomic contact is expected between the wetted side of the oxide film and Fe-rich phases or aluminum matrix. The oxides are $\mathrm{MgO}, \mathrm{MgO} \mathrm{Al}_{2} \mathrm{O}_{3}, \gamma-\mathrm{Al}_{2} \mathrm{O}_{3}$, and $\alpha-\mathrm{Al}_{2} \mathrm{O}_{3} \cdot{ }^{[43,44]}$ Puncreobutr ${ }^{[19]}$ noticed that about 64 pct of observed intermetallics nucleated "on/near" $\alpha-\mathrm{Al}$ dendrites and about 20 pct as self-nucleation where $\beta$ acted as nucleation sites, while oxides presented as minor mechanism. In our experiment, we used high purity elements, but before processing in Artemis, the specimens were poured into a mold, which could cause some oxides to be entrained in our specimens and these might have been collected near casting porosities.

In the Al-7 wt pet Si-1.0 wt pet Fe alloy solidified with large porosity, the platelet A (Figures 10 and 14) 
that was observed to go deeper into the melt ends its growth after crossing precipitate B. Going deeper into melt means going farther from the melt-pore interface and farther from specimen center and in the direction of the lower $\mathrm{Fe}$ concentration. In addition, in the Al-9 wt pet Si-0.2 wt pet Fe alloy, a porosity also occurred but these large intermetallics did not form on the interface melt-pore. The tendency for nucleation on small entrained oxide films ${ }^{[4,16,40,41,44]}$ suggests that $\beta$ nucleated on the melt-pore interface and grew as large due to a high Fe concentration (near pore in Al-7 wt pct Si-1.0 wt pet Fe alloy), or did not reach large sizes due to low Fe content, or disappeared in the absence of $\mathrm{Fe}$ (in Al-9 wt pet Si-0.2 wt pct Fe alloy). The tendency of Fe-rich intermetallics to grow along oxide films ${ }^{[4,44]}$ and the privileged location of the oxides on the melt-surface (high density of oxides as nucleants), together with the high $\mathrm{Fe}$ concentration near the porosity surface (segregation in the specimen center ${ }^{[30]}$, could explain the location, orientation, and the large sizes of the $\beta-\mathrm{Al}_{5} \mathrm{FeSi}$ observed in $3 \mathrm{D}$ X-ray tomography (Figure 14). This observation suggests that the meltgas interface favors $\beta$ nucleation, and high $\mathrm{Fe}$ content supports growth of large platelets. The precise position on the interface and the propeller shape of the $\beta-\mathrm{Al}_{5} \mathrm{FeSi}$ (Figures 10 and 14) imply that growth or following $\beta$ deformation was determined by the melt-pore interface or interaction with the dendrite tip (Figure 10(c)).

\section{B. Morphology Due to Growth of $\beta-\mathrm{Al}_{5} \mathrm{FeSi}$ Phases}

Formation of $\beta-\mathrm{Al}_{5} \mathrm{FeSi}$ depends on many factors, including solidification conditions and chemical composition. Considering the mentioned alloys (Figure 1) and compositions following from fluid flow and segregation and analyzing the solidification path on the basis of the ternary Al-Fe-Si phase diagram (Figure 4), we can distinguish predominant group of alloys and areas where first primary $\alpha$-Al forms, then $\beta$ - $\mathrm{Al}_{5} \mathrm{FeSi}$ phases follow and finally eutectics. For AlSi5Fel (Figure 4, blue line), first $\alpha$-Al forms at the $901 \mathrm{~K}\left(628^{\circ} \mathrm{C}\right)(\mathrm{L} \rightarrow$ $\alpha-\mathrm{Al}+\mathrm{L})$, then enriches in $\mathrm{Si}$ to a concentration of 7.2 pct $\mathrm{Si}$ and 1.5 pct $\mathrm{Fe}$ and reaches the eutectic reaction at $888 \mathrm{~K}\left(615^{\circ} \mathrm{C}\right)$. Next solidification follows the eutectic groove $L \rightarrow \alpha-\mathrm{Al}+\beta-\mathrm{Al}_{5} \mathrm{FeSi}+\mathrm{L}$ starting from $888 \mathrm{~K}\left(615^{\circ} \mathrm{C}\right)$ and ends at $850 \mathrm{~K}\left(577^{\circ} \mathrm{C}\right)$ where final eutectic reaction $L \rightarrow \alpha-\mathrm{Al}+\beta-\mathrm{Al}_{5} \mathrm{FeSi}+\mathrm{Si}$ occurs. The nucleation of $\beta$ platelets occurs in the interdendritic liquid that is supersaturated in $\mathrm{Fe}$ and $\mathrm{Si}$ due to solute rejection by the dendrites already formed.

The second group contains the samples of A1Si5/7/ $9 \mathrm{Fe} 1$ alloys that solidify in the specimen center, where the compositions of AlSi8.5Fe1.8 (for A1Si5Fel alloy) and AlSil1Fe1.8 (for AlSi7/9Fel alloys) have been reached (three alloys) as effect of stirring. Based on the ternary Al-Si-Fe phase diagram (Figure 4), the first solidifying phase is $\beta-\mathrm{Al}_{5} \mathrm{FeSi}$ in this group. For $\mathrm{AlSi} 7$ 9Fel alloys, the first $\beta$ appears at $901 \mathrm{~K}\left(628^{\circ} \mathrm{C}\right)$ and grows until the melt reaches the eutectic groove, where $\alpha$-Al dendrites grow $L \rightarrow \alpha-\mathrm{Al}+\beta-\mathrm{Al}_{5} \mathrm{FeSi}+\mathrm{L}$, and finally, the ternary eutectic reaction occurs. The nucleation of $\beta$ platelets occurs in the liquid melt before the dendrites form.

The third group comprises the alloy with a composition of $\mathrm{AlSi} 9 \mathrm{Fe} 02$. First, $\alpha$-Al forms (Figure 4, red line) at $875 \mathrm{~K}\left(602{ }^{\circ} \mathrm{C}\right)$. On further cooling, the melt enriches up to $12.5 \mathrm{wt}$ pet $\mathrm{Si}$ and $0.3 \mathrm{wt}$ pct $\mathrm{Fe}$ and reaches the eutectic valley at $851 \mathrm{~K}\left(578{ }^{\circ} \mathrm{C}\right)$, which it follows until $850 \mathrm{~K}\left(577^{\circ} \mathrm{C}\right)$, where the final ternary eutectic reaction $L \rightarrow \alpha-\mathrm{Al}+\beta-\mathrm{Al}_{5} \mathrm{FeSi}+\mathrm{Si}$ occurs. This AlSi9Fe02 alloy is below the critical iron content, ${ }^{[4]}$ and the amount of iron can be tolerated before the $\beta$-phase starts to form prior to the Al-Si eutectic. From these all studied alloys, we can distinguish two groups of alloys: one where dendrites of $\alpha$-Al form primarily (in the area $A$ ) and the second where $\beta$ $\mathrm{Al}_{5} \mathrm{FeSi}$ intermetallics form first (area $D$ in the specimens AlSi5/7/9Fe1).

For the alloys where dendrites precipitate first, the distance from the dendrite tips to the ternary eutectic, and thus the length of the mushy zone, can attain different values. For AlSi5Fe1, this is about $17 \mathrm{~mm}$; for AlSi7Fe1, it is about $12.6 \mathrm{~mm}$; and for AlSi9Fe02, it is only $8.3 \mathrm{~mm}$ with temperature gradient $3 \mathrm{~K} / \mathrm{mm}$. For the alloys where $\beta$ forms first (e.g., AlSil1Fe1.8), the zone in which only $\beta$ phase particles grow (distance from liquid to dendrite tips) is $7.6 \mathrm{~mm}$, and then the distance from dendrites tips to the ternary eutectic point is $9.3 \mathrm{~mm}$. For AlSi7Fe1, ${ }^{[32]}$ the primary dendrite spacing can be 300 to $600 \mu \mathrm{m}$ and SDAS 60 to $100 \mu \mathrm{m}$. This means that only limited space is available for $\beta-\mathrm{Al}_{5} \mathrm{FeSi}$ to grow straight in the interdendritic bulk. The isoconcentration lines and the pile-up of solute in the interdendritic liquid shape the $\beta$ plates by forcing them to grow mirroring the surrounding dendrites.

Simulation results ${ }^{[28,29]}$ show that in specimens with $8 \mathrm{~mm}$ diameter, a RMF of $6 \mathrm{mT}$ causes a main azimuthal flow (Figure 15, dashed thick red line) that reaches a value of $10 \mathrm{~mm} / \mathrm{s}$. The azimuthal flow always is accompanied by secondary, meridional flows (Figure 15,

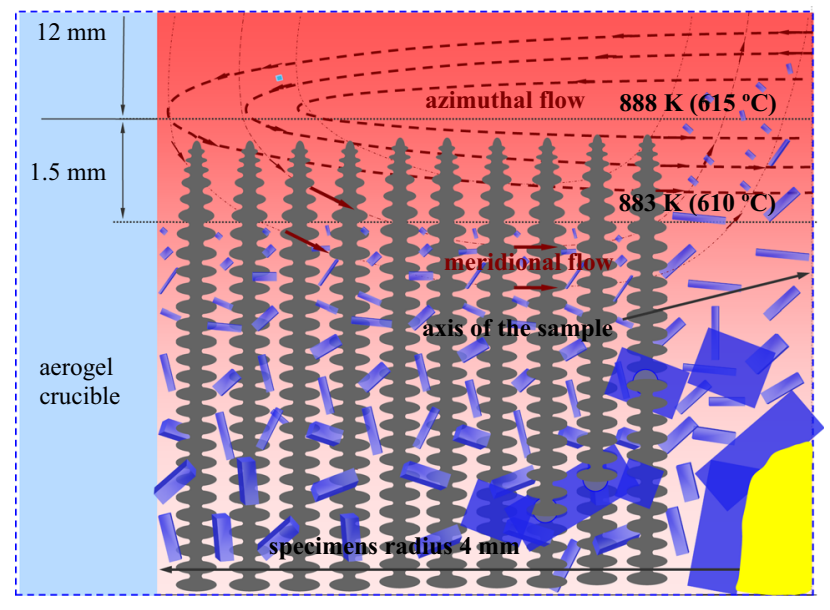

Fig. 15-Scheme of the half of the sample (area $G$ on Fig. 2(a)) solidifying in Artemis with showed mushy zone, dendrites (gray), $\beta$-Al5FeSi platelets (blue), melt (red) and porosity (yellow), azimuthal flow (dashed thick red line), and meridional flow (dashed-dotted thin red line). (For interpretation of the references to color in this figure legend, the reader is referred to the web version of this article.). 
dashed-dotted thin red line) in radial and axial directions with almost the same velocity of $10 \mathrm{~mm} / \mathrm{s} .{ }^{[28,29]}$ Note that the Taylor number describing the flow and the Reynolds number are such that a laminar flow would exist in the melt if no mushy zone existed. ${ }^{[28,29]}$ The amplitude of the azimuthal flow velocity vector increases from the center to $10 \mathrm{~mm} / \mathrm{s}$ near the surface of the specimen. The meridional flows have their maximum flow velocities at the surface, where they are directed toward the mush, and in the center, where they are directed away from the mush into the melt. These flows interact with the dendritic mush. The flow does not really change the thermal field, since the melt has a low Prandtl number. An essential feature for the interaction is therefore that the fluid flow transports solute in and out of the mush. The $\mathrm{Si}$ and $\mathrm{Fe}$ enrichment in the center due to radial flow leads to a region of strong constitutional supercooling and solidification of eutectic rich melt as well as Fe-rich phases. The radial flow also removes both $\mathrm{Si}$ and $\mathrm{Fe}$ from the outer ring of a sample, thereby lowering their concentrations and leading to a denser dendritic network, with smaller and less Fe-rich phases. Since the permeability of the dendritic network is a strong function of both the fraction solid and the dendrite spacing, the flow is damped rapidly in almost one third of the mush length.

Growth of intermetallics between dendrites and their fixation in the dendritic structure result in the creation of melt flow barriers. ${ }^{[46,47]}$ Blocking the flow can significantly influence mushy zone permeability and thereby the growth of the primary and secondary phases.

\section{The Phenomenon of $\beta$ - $\mathrm{Al}_{5} \mathrm{FeSi}$ Phases Shortening}

The velocity determines the growth of $\beta$ platelets. Analysis of the effect of stirring on $\beta$ phases should consider the influence of forced flow on the temperature field and solute concentration in solidifying alloy. ${ }^{[4,49]}$ Forced flow reduces essentially the solute diffusion layer at the solid liquid interface, and thus reduces the region and amount of constitutional undercooling and affects the evolution of the dendritic morphology in the mush. ${ }^{[50]}$ Stirring, and thus solute transport, could even generate fragmentation of the dendrites accompanied by dendrite arm root remelting or dissolution due to solute transport. ${ }^{[35,51-53]}$ The fluid flow, as used here, has been confirmed to reduce the primary stem spacing and increase the SDAS. ${ }^{[25,27]}$

The $\beta$ needles (marked in blue on Figure 15, which shows area $G$ from Figure 2(a)) start to form a few millimeters behind the dendrite tips. The simulation results ${ }^{[28,29]}$ suggest (as presented on Figure 15) that axial flows might reach $12 \mathrm{~mm}$ deep in the bulk melt, and with a temperature gradient of $G=3{ }^{\circ} \mathrm{C} / \mathrm{mm}$, this would give a temperature range of $36 \mathrm{~K}\left(36{ }^{\circ} \mathrm{C}\right)$ from the dendrite tips into the bulk of the mesh. Melt transports not only solute, as mentioned above, but it also could directly transport small $\beta-\mathrm{Al}_{5} \mathrm{FeSi}$ particles (Figure 15) toward the eutectic center. A few of these $\beta$ platelets will stay in the center and will be entrapped in the highly constitutionally supercooled melt, but a few may also be moved back into the melt and be re-circulated (dissolved partly and grown once they are back in the mush).

A fluid flow rich in Fe will lead to an increased growth of the Fe-platelets, due to Fe enrichment. We expect to see larger $\beta$ platelets in agreement with our own findings and previous ones. ${ }^{[46]}$ Transport of $\beta$ platelets is probably possible only close to the dendrite tips, since a favorable interdendritic permeability occurs and thus better conditions to transport "newly formed and short" intermetallics, as was observed in Reference 30 where RMF caused increase in number density of short phases. The phases are then distributed again in the mush network. This fragmentation and partial dissolution of $\beta-\mathrm{Al}_{5} \mathrm{FeSi}$ can act as nucleation sites and growth centers, causing a higher number density and finally a decrease in $\beta$ needle length in the outer ring (area $A)^{[30]}$ or a small increase in the eutectic center $($ area $D) .{ }^{[30]}$

Fluid flow causes segregation of $\mathrm{Fe}$ and $\mathrm{Si}$ in the center of the specimens and forms regions (e.g., area $A$ and $D$, Figure 2(a)) with different $\beta$ needle length and number density. ${ }^{[30]}$ In this way, the solidified microstructure presents various levels of primary $\alpha-\mathrm{Al}$, eutectics, and intermetallics, resulting in a network of intermetallics and dendrites with various flow possibilities, for example. Fluid flow causes decrease in length of $\beta-\mathrm{Al}_{5} \mathrm{FeSi}$ phases in dendritic region and seems to be a way to avoid detrimental effect of $\beta$ platelets. Simultaneously, melt stirring causes segregation, and eutectic region in that growth of large intermetallics occurs. Understanding the shortening effect of $\beta$ should help in designing proper melt flow in the castings and make use of it to improve casting mechanical properties.

As mentioned above, X-ray tomography revealed that $\beta-\mathrm{Al}_{5} \mathrm{FeSi}$ intermetallics can form not only simple platelets, but also curved, branched, crossing, holeshaped phases, and precipitates with imprints, interacting with dendrites, porosity located and extra-large $\beta$ phases. This leads to formation of large and complex Fe-rich intermetallics. Compound structures, in particular, can form the hole-shaped platelets enclosing two or more dendrites and interacting with them. Growth of large and complex group of intermetallics can cause reduction in the melt flow between dendrites leading to lower permeability of the mushy zone. The fragmentation and shortening of $\beta$ phases mentioned above could be decreased by blockage of the flow between complex intermetallic structures. This should affect $\beta$ phases less, as they are localized deep between dendrites and should have a greater effect on the intermetallics placed near the dendrite tips.

The interaction between melt flow, 3D distribution, and morphology of $\beta-\mathrm{Al}_{5} \mathrm{FeSi}$ can lead to complicated microstructures in castings and varying mechanical properties of alloys and might demand modification in processing technologies. As described above, melt flow influences the distribution of $\beta$ phases in castings, and distribution of $\beta$ precipitates together with segregation of alloying elements determines morphology of $\beta$ intermetallics. Vice versa, the $3 \mathrm{D}$ distribution and morphology influences flow possibilities in castings. 


\section{CONCLUSIONS}

$\mathrm{X}$-ray tomography investigations have been performed on the $\beta-\mathrm{Al}_{5} \mathrm{FeSi}$ phases in $\mathrm{Al}-5 / 7 / 9 \mathrm{wt}$ pct Si$0.2 / 0.5 / 1.0$ wt pet $\mathrm{Fe}$ alloys processed in controlled solidification conditions without and with melt flow generated by rotating magnetic field RMF. The solidified specimens were extensively investigated by X-ray tomography, which revealed the $3 \mathrm{D}$ characteristics of $\beta$ phases and the microstructure. Advancements of the current study lies in the analysis of melt stirring with help of X-ray tomography taking into consideration the $3 \mathrm{D}$ morphology of $\beta-\mathrm{Al}_{5} \mathrm{FeSi}$ phases, and also the first presentation of reveled intermetallic's shapes discussed in aspect of controlled solidification and fluid flow conditions.

1. The study showed 3D distribution of intermetallics in directionally solidified specimens and showed an increase in number density of $\beta$ platelets with melt flow. For the first time, 3D views have shown that fluid flow causes growth of large $\beta-\mathrm{Al}_{5} \mathrm{FeSi}$ intermetallic phases in the specimen center as an effect of melt stirring and that $\mathrm{Fe}$ and $\mathrm{Si}$ segregation occurred.

2. Three-dimensional reconstructions revealed $\beta$-Al $1_{5-}$ FeSi phases with shapes different from simple platelets. X-ray evaluation revealed intermetallics shaped as curved (interaction with dendrites and twining), branched ( $\beta$ nucleating one on the other), holeshaped (lateral growth around dendrites), with imprints (thickening of $\beta$ near dendrites and surface instability), and bent and propeller shaped (interaction with dendrites and melt-pore interface). The privileged growth of $\beta$ phases concentrated around porosity and parallel to the melt-pore interface can cause growth of extra-large $\beta-\mathrm{Al}_{5} \mathrm{FeSi}$.

3. Thermal and flow conditions during $\beta$ intermetallics precipitation were discussed. Analysis of the solidification path revealed two cases: one where $\alpha$-Al dendrites form first (followed by $\beta$ ) and the second where $\beta-\mathrm{Al}_{5} \mathrm{FeSi}$ intermetallics precipitate first. Dendritic morphology by $\beta$ growth showed only limited space for $\beta$ - $\mathrm{Al}_{5} \mathrm{FeSi}$ to grow independently in the interdendritic bulk and unconstrained growth in eutectics. Melt flow (azimuthal and meridional) that reaches about $10 \mathrm{~mm} / \mathrm{s}$ modifies the temperature and solute pile-up and infiltrates the dendritic structure.

4. For the first time, X-ray tomography showed in the 3D geometry the fluid flow effect leading to shortening of $\beta$ intermetallics in dendritic area.

\section{ACKNOWLEDGMENTS}

This work was carried out in the framework of the project "iPhaseFlow" within the confines of Marie Curie Intra European Fellowship, supported by Seventh Framework Program GA Nos. 235874, PIEFGA-2009-235874 of the European Union.

\section{OPEN ACCESS}

This article is distributed under the terms of the Creative Commons Attribution License which permits any use, distribution, and reproduction in any medium, provided the original author(s) and the source are credited.

\section{REFERENCES}

1. P. Skjerpe: Metall. Trans. A, 1987, vol. 18A, p. 189.

2. V.G. Rilvinand and G.V. Raynor: Int. Metall. Rev., 1981, vol. 3, pp. $133-52$.

3. S.G. Shabestari: Mater. Sci. Eng. 2004, A 383, pp. 289-298.

4. W. Khalifa, F.H. Samuel, and J.E. Gruzleski: Metall. Mater. Trans. A, 2003, vol. 34A, pp. 807-25.

5. C.M. Dinnis, J.A. Taylor, and A.K. Dahle: Mater. Sci. Eng. A, 2006, vol. 425, pp. 286-96.

6. P.N. Crepeau: AFS Trans., 1995, vol. 103, p. 361.

7. E. Taghaddos, .M.M. Hejazi, R. Taghiabadi, and S.G. Shabestari: J. Alloys Compd., 2009, vol. 468, pp. 539-45.

8. F.H. Samuel, A.M. Samuel, and H.W. Doty: AFS Trans., 1996, vol. 104, p. 893.

9. V. Firouzdor, M. Rajabi, E. Nejati, and F. Khomamizadeh: Mater. Sci. Eng. A, 2007, vols. 454-455, pp. 528-35.

10. M. Tash, F.H. Samuel, F. Mucciardi, and H.W. Doty: Mater. Sci. Eng. A, 2007, vol. 443, pp. 185-201.

11. N. Iqbal, N.H. van Dijk, S.E. Offerman, M.P. Moret, L. Katgerman, and G.J. Kearley: Acta Mater., 2005, vol. 53, pp. 2875-80.

12. R.H. Mathiesen, L. Arnberg, K. Ramsoskar, T. Weitkamp, C. Rau, and A. Snigirev: Metall. Mater. Trans. B, 2002, vol. 33B, pp. 613-23.

13. S. Terzi, L. Salvo, M. Suery, A.K. Dahle, and E. Boller: Acta Mater., 2010, vol. 58, pp. 20-30.

14. S. Terzi, L. Salvo, M. Suery, N. Limodin, J. Adrien, E. Maire, Y. Pannier, M. Bornert, D. Bernard, M. Felberbaum, M. Rappaz, and E. Boller: Scripta Mater., 2009, vol. 61, pp. 449-52.

15. F. Lasagni, A. Lasagni, E. Marks, C. Holzapfel, F. Mucklich, and H.P. Degisher: Acta Mater., 2007, vol. 55, pp. 3875-82.

16. S. Terzi, J.A. Taylor, Y.H. Cho, L. Salvo, M. Suery, E. Boller, and A.K. Dahle: Acta Mater., 2010, vol. 58, pp. 5370-80.

17. C.M. Dinnis, J.A. Taylor, and A.K. Dahle: Scripta Mater., 2005, vol. 53, pp. 955-58.

18. M. Timpel, N. Wanderka, B.S. Murty, and J. Banhart: Acta Mater., 2010, vol. 58, pp. 6600-08.

19. C. Puncreobutr, A.B. Phillion, J.L. Fife, P. Rockett, A.P. Horsfield, and P.D. Lee: Acta Mater., 2014, vol. 79, pp. 292-303.

20. L. Sweet, S.M. Zhu, S.X. Gao, and J.A. Taylor: Metall. Mater. Trans. A, 2011, vol. 42A, pp. 1737-49.

21. A. Verma, S. Kumar, P.S. Grant, and K.A.Q. O'Reilly: J. Alloys Compd., 2013, vol. 555, pp. 274-82.

22. J. Alkemper, S. Sous, C. Stocker, and L. Ratke: J. Cryst. Growth, 1998, vol. 191, pp. 252-60.

23. S. Sous and L. Ratke: Z. Metall., 2005, vol. 96 (4), pp. 362-69.

24. S. Steinbach: Ph.D. Thesis, RWTH, Aachen, Germany, 2005.

25. S. Steinbach and L. Ratke: Metall. Mater. Trans. A, 2007, vol. 38A, pp. 1388-94.

26. S. Steinbach, N. Euskirchen, V. Witusiewicz, L. Sturz, and L. Ratke: Mater. Sci. Forum, 2006, vols. 519-521, pp. 1795-1800.

27. S. Steinbach, N. Euskirchen, V. Witusiewicz, L. Sturz, and L. Ratke: Trans. Indian Inst. Met., 2007, vol. 60 (2-3), pp. 137-41.

28. M. Hainke: Ph.D. Thesis, Technical Faculty Erlangen-Nuremberg, Germany, 2004.

29. S. Steinbach: Institut für Materialphysik im Weltraum, German Aerospace Center DLR, Linder Höhe, Köln, Germany, unpublished research, 2014.

30. P. Mikolajczak and L. Ratke: Int. J. Cast Met. Res., 2013, vol. 26, pp. 339-53.

31. P. Mikolajczak and L. Ratke: The Minerals, Metals \& Materials Society (TMS), Supplemental Proceedings: General Paper Selections, Volume 3, John Wiley \& Sons, Inc., Hoboken, NJ, 2011. 
32. P. Mikolajczak and L. Ratke: IOP Conf. Ser., Mater. Sci. Eng., 2012, vol. 27, p. 012024.

33. J. Wang, P.D. Lee, R.W. Hamilton, M. Li, and J. Allison: Scripta Mater., 2009, vol. 60, pp. 516-19.

34. X. Fang, G. Shao, Y.Q. Liu, and Z. Fan: Mater. Sci. Eng. A, 2007, vols. 445-446, pp. 65-72.

35. S. Nafisi, D. Emadi, M.T. Shehata, and R. Ghomashi: Mater. Sci. Eng. A, 2006, vol. 432, pp. 71-83.

36. U. Hecht and S. Rex: Proc. Int. Conf. on the Science of Casting and Solidification, Brasov, Romania, 2001, pp. 53-59.

37. P. Mikolajczak and L. Ratke: Arch. Foundry Eng., 2013, vol. 13, pp. 79-82.

38. L.A. Narayanan, F.H. Samuel, and J.E. Gruzleski: Metall. Mater. Trans. A, 1994, vol. 25A, pp. 1761-73.

39. D.N. Miller, L. Lu, and A.K. Dahle: Metall. Mater. Trans. B, 2006, vol. 37B, pp. 873-78.

40. Y.H. Cho, H.C. Lee, K.H. Oh, and A.K. Dahle: Metall. Mater. Trans. A, 2008, vol. 39A, pp. 2435-48.

41. K. Nogita, S.D. McDonald, K. Tsujimoto, K. Yasuda, and A.K. Dahle: J. Electron Microsc., 2004, vol. 53, pp. 361-69.

42. X. Cao and J. Campbell: Metall. Mater. Trans. A, 2003, vol. 34A, pp. 1409-20.
43. L. Lu and A.K. Dahle: Metall. Mater. Trans. A, 2005, vol. 36A, pp. 819-35.

44. S. Nafisi and R. Ghomashchi: J. Alloys Compd., 2007, vol. 436, pp. 86-90.

45. J. Taylor: Proc. Mater. Sci., 2012, vol. 1, pp. 19-33.

46. S. Steinbach and L. Ratke: Int. J. Cast Met. Res., 2009, vol. 22, pp. 290-93.

47. C. Puncreobutr, A.B. Phillion, J.L. Fife, and P.D. Lee: Acta Mater., 2014, vol. 64, pp. 316-25.

48. W. Kurz and D.J. Fisher: Fundamentals of Solidification, Trans Tech Publications, Aedermannsdorf, Switzerland, 1986.

49. J.A. Dantzig and M. Rappaz: Solidification, EPFL Press, Switzerland, 2009.

50. A. Das, S. Ji, and Z. Fan: Acta Mater., 2002, vol. 50, pp. 457185.

51. S. Nafisi and R. Ghomashchi: Mater. Sci. Eng. A, 2006, vol. 437, pp. 388-95.

52. X. Li, Y. Fautrelle, and Z. Ren: Acta Mater., 2008, vol. 56, pp. $3146-61$.

53. M.C. Flemings: Solidification Processing, McGraw Hill, New York, 1974. 